\title{
EL CONTEXTO SOCIOCULTURAL EN LA ADQUISICIÓN DE LA LENGUA TZELTAL ${ }^{1 *}$
}

por Brian STROss, Universidad de Texas

Es evidente que la adquisición del lenguaje por los niños no ocurre ni podría ocurrir en un vacío social o lingüístico. Aunque se ha discutido bastante la naturaleza de la capacidad innata de un niño para aprender el lenguaje (cf. McNeill, 1966), y el significado de un "componente madurativo" para determinar la proporción y dirección del desarrollo del lenguaje (Lenneberg, 1967), es indiscutible que la forma y el contenido de información (imput) lingüística que recibe el niño restringe críticamente la forma y contenido de su habilidad lingüística esencial. Esto queda claro en el hecho de que un niño que ha escuchado solamente inglés no terminará hablando ni ruso ni japonés. De hecho, un niño normal crece hablando una lengua que se asemeja enormemente a la que hablan los otros miembros de su comunidad lingǘstica. Pero el niño no puede asimilar su repertorio total de unidades lingüísticas ni todas las reglas que a ellas se refieren de una sola vez. Debe estar expuesto por algún tiempo a ejemplos de unidades relacionadas que incluyen las reglas. Tal exposición ocurre, generalmente, a lo largo de la vida de una persona y es posible que ésta esté aprendiendo durante la mayor parte del tiempo. El desarrollo del lenguaje, sin embargo, ocurre más rápidamente en la infancia y de hecho se acepta generalmente que

- Tradujo del inglés Cecilia Tercero.

${ }^{1}$ El trabajo de campo se llevó a cabo entre los meses de julio de 1967 a junio de 1968, y en el verano de 1970. Las National Institutes of Health financiaron mis viajes y estudios. El National Institute of General Medical Sciences (documento nú. mero GM 1224), de 1967 a 1968; en 1970 por la National Science Foundation USDP, documento número GU 1598. Debo agradecer ante todo a Brent Berlin por sus comentarios críticos y la lectura de un borrador anterior, y a Dennis E. Breedlove por haber identificado las plantas. Además a Ben Blount, Keith y Claudia Kernan, a Mary Sanches y Joel Sherzer por sus estímulos intelectuales y sus comentarios a partes de este trabajo. Sin embargo, la responsabilidad de lo que digo en él es solamente mía. 
el grueso de reglas gramaticales y sintácticas se aprendan en el breve lapso entre los dos años y medio y los cinco. La habilidad sociolingüística se adquiere, aparentemente con mayor lentitud.

Durante la adquisición de la habilidad lingüística y sociolingüística, el niño está expuesto a una gran cantidad de formas de lenguaje, estilos, códigos, rutinas, etcétera de diversas personas; y es la totalidad de información lingüística recibida, lenguaje escuchado tanto como lenguaje dirigido al niño, que conforma y delimita su capacidad para comprender el lenguaje y para expresarse debidamente. Las normas de conducta y los ideales sociales, los sistemas de creencias, los moldes de la comunidad, consideraciones económicas y aspectos estructurales de familia y parentesco, todo tiene un efecto en quién habla a qué niño, con cuánta frecuencia, igualmente que cómo, cuándo, dónde, sobre qué temas, en qué estilos y bajo qué circunstancias. Si la adquisición del lenguaje está unida a la estructura social y a los factores culturales a través de la información lingüística que se da al niño, es natural que el estudio de la adquisición del lenguaje se beneficiará si se delinean las actitudes y prácticas culturales que influyen la información lingüística que se da al niño. El problema es hacerlo así sin introducir al mismo tiempo una cantidad excesiva de material etnográfico diverso, pero sin llegar tampoco al otro extremo de presentar algunos informes breves, necesariamente engañosos, incompletos y simplificados en extremo, acerca de la red de interacción del niño en una sociedad particular. Aquí adoptamos un enfoque intermedio en la presentación de los hechos, relacionados con la información lingüística que se da al niño.

Este enfoque es descriptivo, dirigido a la infancia en el ciclo de vida de los tzeltales de Tenejapa, estudiando sobre todo el embarazo, el nacimiento y las prácticas y creencias que se usan para educar a los niños. Relacionados con este tema, se incluyen algunos datos adicionales sobre religión, los moldes de adaptación, los hábitos de juego, las redes de interacción y la vida política según el grado de importancia directa para la información y conducta lingüísticas del niño en el primer ciclo de la vida. Donde fue posible, explicamos la relación entre factores sociales y el uso del lenguaje. Discutimos también los importantes temas que son el habla infantil, las correcciones que los padres hacen de este lenguaje, los juegos del lenguaje y competencias verbales entre los niños, los defectos de lenguaje, los castigos verbales por mala conducta, la participación del niño en conversaciones entre adultos y los tabúes lingüísticos. Es claro que este enfoque debe omitir algunos hechos relativos al mismo, e incluir 
material, en la creencia de que demasiados detalles etnográficos no sacrificarán la claridad y pueden ayudar a la continuidad de la exposición. Además, la escasez de relatos etnográficos disponibles sobre los tzeltales parecería indicar la necesidad de datos publicados, acerca de este pueblo inadecuadamente descrito que, en los próximos años sufrirá un rápido cambio cultural ya que esta región se ha ido abriendo cada vez más gracias a los caminos y las escuelas.

El tzeltal forma parte de la familia lingüística maya; lo hablan aproximadamente 125000 personas que habitan la región central de las tierras altas de Chiapas, México. El grupo lingüístico tzeltal comprende unos dieciocho dialectos. Uno de éstos es el de Tenejapa, donde viven cerca de 12000 indígenas en los 67 kilómetros cuadrados del municipio.

La mayoría de personas que hablan el dialecto de Tenejapa no hablan otra lengua, algunos hablan el español local con considerable soltura y muchos conocen apenas algunas palabras españolas. Las mujeres tienden a ocultar su conocimiento del español, los hombres a demostrarlo.

Los tzeltales de Tenejapa, al igual que sus vecinos los tzeltales y tzotziles, son campesinos sedentarios que usan los métodos de tala y roza para producir una cosecha de maíz y frijol que apenas les produce lo suficiente para subsistir. Las unidades de producción y consumo de cada familia, ocupan chozas de un cuarto único con techo de paja que se agrupan en aldeas llamadas parajes, los que rodean su centro ceremonial, la cabecera del municipio. Este centro político y religioso de los indígenas es una comunidad predominantemente mestiza.

Aunque son cien o más las familias mestizas que viven permanentemente en Tenejapa, casi ninguno de estos mestizos vive en los parajes circundantes. Algunos indígenas tienen casas en las cabeceras pero muy pocos residen en ella permanentemente. Las familias de los indígenas que desempeñan cargos importantes en la jerarquía civil o religiosa van a vivir a la cabecera durante el año que dura el encargo. Frecuentemente viven en casas rentadas o prestadas y regresan a sus lugares de origen al final del año. Tenejapa se encuentra a poco más de 30 kilómetros al noreste de San Cristóbal de las Casas.

Durante la estación seca se puede llegar a Tenejapa en jeep; el viaje dura de tres a cinco horas; a pie se hacen de cinco a siete horas. Dentro de algunos años se podrá llegar a Tenejapa en coche; la carretera ya está en construcción. 


\section{Significado y valor de los niños}

Un niño de cualquier sexo es siempre bienvenido en las familias de Tenejapa, pues los niños significan manos extras para ayudar con el trabajo de la casa, del campo y otros menesteres. Desean a los niños por ellos mismos y también para ellas. Se dice que es una casa triste aquella en la que no hay niños que rían, griten y jueguen. Sin embargo, los niños varones son más apreciados que las niñas.

De poder escoger entre niños y niñas los tzeltales de Tenejapa entrevistados, eligirían a los niños, pues éstos heredan las tierras, mantienen lazos económicos más fuertes con sus familias durante toda la vida y son un sustituto del padre y del abuelo para continuar la línea de la familia. Sin embargo, no es raro que una mujer prefiera a una hija para hablar con ella y para que le ayude en las tareas caseras.

\section{Abortos $y$ esterilidad}

Dado el valor social y económico de los niños, no es sorprendente que el aborto casi no exista entre las mujeres casadas y que éstas tengan una serie de remedios caseros para la esterilidad. Se espera generalmente que una pareja adulta que hace vida común empezará a tener hijos en los primeros dos o tres años. Si al cabo de este tiempo todavía no los tienen, probablemente la mujer recurrirá a las plegarias y a las pócimas, remedios con que trata de aumentar su fertilidad.

Una de estas pócimas consiste en pólvora negra (sibak), ${ }^{2}$ que se mezcla en una olla de calabaza, llena de agua hasta la mitad. Se cree comúnmente que la mujer que toma esta mezcla debería quedar embarazada en pocos meses si repite correctamente la dosis en dos o tres días diferentes. Sin embargo, si toma esta medicina cuando ya tiene un niño, este niño morirá, aunque la pócima no afectará al niño que no ha nacido todavía. Otros productos que se emplean para provocar la concepción son el azufre, el alcanfor y la pimienta negra, usados en la misma forma que la pólvora negra. Existen además, en la región, una serie de plantas que crecen allí, conocidas por sus propiedades fertilizantes y que se emplean llegado el caso.

\footnotetext{
2 Incluyo en este trabajo palabras y expresiones tzeltales por dos razones; 1) para facilitar la verificación y réplica de los datos y 2) para distinguir entre varias alternativas en los casos en que la forma inglesa tiene varios posibles equivalentes en tzeltal.
} 
Entre éstas se encuentran el payte? (yerba no identificada), el bakte?poš (no identificada) y sansire ?ak (Cymbopogon citratus, Stapf.). Se cree generalmente que son las raíces de las plantas las que tienen el poder de ayudar a las mujeres a tener hijos.

Después de tres o cuatro años de hacer vida común, cuando es claro que la pareja no tendrá hijos, el hombre puede buscar a otra mujer para aumentar así su familia. La mujer estéril puede ser abandonada o no, y puede regresar con su familia o formar una unión (formal o informal) con otro hombre. La esterilidad es motivo suficiente para el divorcio.

Se cree que una especie de oruga con cuernos (buluk' sit) vive en la matriz de la mujer estéril, y que a media noche sale a mamar. Se supone que el buluk' sit mide $7.5 \mathrm{~cm}$. de largo, es más grueso que un dedo pulgar y tiene una boca grande con la que mama. Hay una historia que cuenta que antiguamente el buluk' sit podía hablar y solía llamar a su "papá", el esposo de la mujer estéril que estaba trabajando en la milpa, pidiéndole que regresara y le llevara su comida de atole de maíz ( $m a c$ ', una metáfora común para "semen"). Un día, la gente lo oyó gritar y planeó ir a buscarlo. Finalmente lo encontraron sentado en el tallo de una chayotera (č'omate? metáfora común de los genitales femeninos). Se dice que la mujer que tiene un buluk' sit es estéril porque la oruga ocupa el lugar del posible bebe y por ello está agotando la capacidad limitada de la desventurada mujer.

Pero no siempre se culpa a la mujer si un matrimonio no tiene hijos. Si se sabe que la mujer es capaz de tener hijos, tal vez por una unión anterior, entonces se piensa que el esposo es el culpable. Se cree que tiene un fluido seminal claro, acuoso ( $k$ 'anal Pišim, literalmente "maíz amarillo", o sikil nal, literalmente "semen frío"). Se reconoce su esterilidad si es incapaz de tener hijos con otra esposa o si de antemano se sabe que su esposa es fértil. Los hombres impotentes son el blanco de burlas y chanzas, hechas generalmente en su ausencia. Uno de estos hombres que vive en el paraje de Mahosik' es un anciano alférez casado con una mujer joven y atractiva que ansía tener hijos. Puesto que se cree que ocurrirá una muerte determinada a la mujer infiel de un alférez, este hombre viejo acepta un cargo religioso todos los años, para impedir que su mujer acepte la ayuda de otro hombre para conseguir el niño que tanto desea. Esto es lo que se rumora sobre el aparente fervor de este hombre para servir a su comunidad. Otro hombre que vive en Mahosik' y que se creía impotente, estuvo muchos años sin tener hijos. Cuando 
finalmente su esposa dio a luz a un varón, se murmuraba en todo el paraje que el hermano de este hombre le hizo un favor al fecundar a su esposa, para que al fin pudiera tener el hijo que tanto ansiaba.

\section{Concepción}

En la teoría popular el papel del hombre en la concepción es mucho más elaborado. Se cree que el hombre posee un órgano que se encuentra en alguna parte del torso inferior y que se llama $m e^{2}$ winik. $\mathrm{Si}$ una mujer tiene hijas solamente, entonces su esposo tiene un 'ancil me? winik ('ancil, "niña"). Si solamente tiene niños, o niñas y niños, entonces el padre debe tener un kelem meiwinik (kelem, "niño"). Las mujeres tienen también un me winik, que, sin embargo, es del tipo ?ancil, por lo que no desempeña ningún papel activo en la decisión del sexo de los niños.

Por el gran valor que tienen los niños, generalmente una mujer está muy contenta cuando "no ve su sangre menstrual" ( $m a^{2} b a$ yil spat) durante esa fase de la luna en que ella sabe que debe bajar. Orgullosamente dice a su esposo: "No vi la luna" ( $m a^{2} b a$ kil bčulme tik), para que pueda comenzar a contar los meses, y anticipar el momento del nacimiento. Durante el embarazo, en una de las regiones más conservadoras de Tenejapa, los meses se cuentan anotando todas las veces que la luna está en fase determinada en el cielo. Si la luna estaba en su cuarto menguante cuando la mujer dejó de menstruar, entonces los meses de embarazo igualan al número de cuartos menguantes que ocurren, incluyendo el primero. Esposos más civilizados emplean un calendario en el que marcan los meses del embarazo.

\section{Embarazo}

Muchos tenejapeños creen que los niños nacen después de una gestación de diez u once meses. Según la tradición, un niño que nazca después de los once meses, será un niño sano y fuerte, pero si nace a los diez, será débil. Una niña de diez meses, será fuerte, pero si nace después de los nueves meses, será débil. Estos cálculos del periodo de gestación, aparentemente largos si los comparamos con los nuestros, se deben tal vez a que se cuenta como el primer mes, la fase de la luna en que por primera vez falta la sangre, y a que el cielo lunar es más corto que un mes calendárico. 
Desde el momento de la concepción (ya yič' makel 'alal) hasta el momento del nacimiento ( $y a$ štohk ?alal) se llama al desarrollo del embrión y del feto hunbil 'alal, puesto que durante este tiempo el bebe "acompaña" a la madre, comparte con ella el aire que respira y se alimenta de la sangre menstrual que ya no fluye. Se cree que al principio el feto tiene la forma de una rata pequeña ('unin č'o), pero en el momento en que comienza a moverse un poco, ya ha empezado a tomar forma humana. Se cree que el feto se encuentra siempre con la cabeza hacia abajo. En el Apéndice $A$ incluyo las fases del desarrollo fetal.

El alma (č'ulel) puede entrar a la matriz a reunirse con el futuro niño poco después de la concepción, según algunos informantes, aunque según otros, cuerpo y alma se reúnen sólo después de que el feto ha comenzado a moverse y ha tomado forma humana. El destino de una persona, desde la concepción hasta la muerte depende fuertemente de la suerte, las condiciones y los deseos de su č'ulel. Si un č'ulel es lo bastante inquieto, como lo es algunas veces, se saldrá del vientre de una mujer para entrar en el de otra, llevándose consigo al feto. La mujer en la que se refugia tendrá a su hijo en ocho meses; se trata invariablemente de una mujer casada. La mayoría de los abortos se explican de esta manera, y se cree que esa pérdida del feto ocurrirá en los primeros tres meses del embarazo.

Puesto que siempre existirá la posibilidad de perder al hijo, una mujer embarazada rezará y ayunará algunas veces, para prevenir que se escape su alma, o alguna otra desgracia. Podrá rezar una vez por semana o $\tan$ poco frecuentemente como cualquier otro mes, dependiendo de su estado de ansiedad. En sus oraciones llamará a la madre tierra (bme $e^{2} t i k$ kašeltik), a los dioses ancestrales (bme'tiktatik) y a una serie de santos asociados con la "iglesia" local, y pedirá su ayuda para asegurarse un parto seguro y feliz. Las oraciones se dicen también para alejar las malas influencias que resultan de la envidia de otros o por la transgresión accidental de tabúes prenatales. Además, la futura madre o alguna pariente cercana pedirá que el niño no resulte ser tartamudo, ladrón o borracho, que no tenga labio leporino o algún otro atributo negativo. Las oraciones pueden hacerse cualquier día menos en lunes que es un día negativo o potencialmente malo. En Tenejapa nadie reza los lunes por ningún motivo.

La envidia o su consecuencia directa, la brujería, son muy temidas por la mujer embarazada. Se sabe ampliamente en Tenejapa que una mujer pobre o estéril estará celosa de otras mujeres más afor- 
tunadas y hablará y pensará en ellas con envidia. Podrá pensar y decir a alguna pariente: "¿Por qué esa persona tiene tanto? No lo merece. Sería bueno que le pasara algo malo para demostrárselo. Uno de sus hijos debería morir, o el que espera debería ser niña. Eso le enseñaría". Habladurías maliciosas como ésta se llaman bešbuntael. Pero existe además una forma más activa de envidia, tawaltael, que implica rezos perversos y brujería. Una persona envidiosa puede causar una enfermedad o la muerte al hijo de alguien, hacer que una mujer embarazada aborte, o cambiar el sexo de un feto que debía haber sido varón. La brujería, consecuencia de la envidia, puede hacer que crezca un sapo (špok'ok), un burro (buro) o un mono ( $m a s ̌)$ en el vientre de una mujer casada, y que nazca muerto entre los tres $\mathrm{u}$ ocho meses después de que la mujer ya no ve su sangre. Se cree que es más probable que la hostilidad, la envidia y la brujería provengan de los parientes cercanos, especialmente de los hermanos del mismo sexo.

Se cree que la brujería contra una mujer embarazada será más eficaz, si su esposo no la acompaña en la noche cuando tiene que salir de la casa a orinar. Si el esposo no está en casa, entonces otra persona de la familia deberá acompañarla, y a menos que haya una luna brillante, deberán alumbrar el camino con brea o una linterna. Si una mujer embarazada saliera sola y en la oscuridad, correría también el peligro de ser "golpeada por los dioses ancestrales" (ya šmahot bme?tiktatik) y perdería a su hijo.

Existen otras prohibiciones para la mujer embarazada. Aunque puede tejer, hacer el quehacer de la casa y continuar las relaciones sexuales hasta el parto, se supone que no acarreará leña, y no hará ningún trabajo largo o pesado. No caminará tanto como de costumbre ni recorrerá distancias largas, como ir a la plaza (č'iwič), ya que esto aumentaría las posibilidades de encontrar influencias maléficas. No debería pasar cerca de una cruz en una vereda a medio día o al atardecer. Hasta los hombres pueden enfermarse si pasan cerca de una cruz en el camino a mediodía, pues estos lugares sagrados pertenecen a los dioses ancestrales y traen también al alma humana (č'ulel). La mujer embarazada tampoco puede negarse ningún antojo de comida. La violación de alguna de estas restricciones puede provocar un aborto (ya šk'aš 'alal).

Una mujer embarazada no debe mirar a una serpiente, pues se cree que si viera las escamas de cualquier serpiente, el nacimiento de su hijo se retrasaría dos o tres meses. La posibilidad de cruzarse o de ver a una serpiente es otra razón para la prohibición de no 
caminar mucho. Se dice también que no debería ver a un borrego ni a una cabra muertos, pues esto provocaría que su hijo naciera con los ojos malos, ojos parecidos a los de un borrego. Algunos informantes tzeltales aseguran que los ojos de un borrego muerto están siempre abiertos y que es eso lo que en cierta forma explica la prohibición prenatal. La mujer que espera, tampoco debería mirar la cabeza de un toro muerto, para evitar que su hijo nazca con los ojos malos. Se considera también potencialmente mala, aunque sin especificar cómo, la presencia de cadáveres humanos a un niño que no ha nacido todavía, especialmente si la madre mira al cadáver.

La mujer embarazada no debería reírse ni burlarse de enanos, ni personas feas, de corta estatura, de piel oscura, paralíticas, tartamudas, mudas, tuertas o ciegas, sordas, con labios leporinos, de mujeres ancianas que ansían tener relaciones sexuales, de borrachos, ladrones, jorobados, pobres, personas con la nariz roma o con algún otro defecto ya sea físico o moral. La tradición afirma que si ofendiera verbalmente a otro por defectos como los anteriormente descritos, su hijo resultaría con defectos como los que había ridiculizado. Tampoco puede hacer bromas acerca de los conejos, pues esto provocaría que su hijo naciera con un labio leporino.

Si una mujer embarazada siente una fuerte atracción por el hijo de alguna otra persona, se piensa que su hijo se parecerá al niño admirado. Muchas mujeres embarazadas creen también que es más probable que durante Navidad tengan un niño del mismo sexo que la figura del Cristo expuesta en la iglesia de la cabecera en ese momento. Aunque en Tenejapa existen tanto un Cristo niño como un Cristo niña, sólo uno es el que se expone en un año dado; se dice que alternan.

Una mujer embarazada puede soñar que tiene relaciones sexuales con un mestizo (bkašlan) o con algún indígena que no sea su esposo. Se cree que tal sueño anuncia la pérdida de su hijo por aborto, pues el otro hombre es en realidad un "mono-niña" ('ancil maš) o un "mono-niño" (kelem maš) pues estos dos seres sobrenaturales jamás aparecen en su forma verdadera en los sueños de los humanos. Si fuera un "mono-niña" la mujer tendría un aborto, aunque podría seguir teniendo hijos. Pero si fuera un "mono-niño" tendría un aborto y nunca volvería a tener hijos, a menos que pudiera aplicar con éxito las plegarias y una o varias de las pócimas de fertilidad que usan las mujeres. Si repite la medicina, una mujer que ha visto al "mono-niño" y perdido a su hijo, verá en algunas ocasiones que esta medicina sí sirve. 
Puesto que puede causar envidia a otras personas, una mujer que sabe que está embarazada, generalmente tendrá cuidado al anunciar su buena fortuna fuera de su casa. Pero, por otra parte hay algunas personas a quienes tiene que decirlo, y tiene buenas razones para hacerlo. Primero lo dice a su esposo, después a su suegra, y sólo después de algunos días es que lo anuncia a sus propios padres. $\mathrm{Si}$ las familias de sus padres y suegros son grandes, la noticia correrá pronto.

Se piensa que avisar a los parientes resulta benéfico para el futuro niño, a pesar de los peligros que entraña causar la envidia de otros, pues se cree que esto obliga al feto a alcanzar pronto la etapa en que hace ruidos ( $y a$ šlibk buk'ubabuk), la etapa de balbucear (ya šlibk bamuk stî) y a que aprenda a hablar pronto y bien. Si por otra parte, la mujer guarda el secreto cuando ya no ve su sangre, se cree que el niño tardará mucho en aprender a hablar.

Durante el cuarto mes de embarazo la mujer va con una parienta mayor para que le ajuste el vientre (bačel te šč'ubte), por medio de masajes y manipulaciones. A esta parienta se da entonces el nombre temporal de "criadora" (bač ?alal). En los meses siguientes la mujer embarazada visita algunas veces a la "criadora" para que la revise, muy poco al principio y con mayor frecuencia después. Al acercarse el momento del parto, puede visitar a la "criadora" una vez a la semana, para que le ajuste el vientre, de modo que el feto se encuentre en posición correcta.

Aproximadamente un mes antes del parto se llama a un curandero ( $b p o s ̌ i l)$ para que la revise, tome su pulso (ya spik sk'ab) y prediga el sexo del niño; para aconsejarle qué oraciones rezar y así asegurar un parto fácil, tanto como para proteger su propia vida y la del niño y para prepararla para la prueba que la espera con un breve ritual en el que se bebe.

Habiendo orado en el sitio de la casa donde se encuentra la cruz, el curandero mezcla semillas de kašlan tunim (un arbusto no identificado) en una calabaza llena de agua, y después sopla y reza sobre la cocción. El ritual de soplar (tubtael) se describe más exactamente como soplar y escupir. Una vez que se ha hecho todo lo necesario, la mujer bebe de la calabaza. Una parienta de más edad de la mujer embarazada puede sustituir al curandero para la ayuda futura hasta el parto, y con frecuencia lo hace. Contrariamente a otros municipios tzeltales, Tenejapa no utiliza los servicios de parteras profesionales. 


\section{NACIMIENTO}

Parto

Más o menos un mes después del ritual preparatorio, una vez que los dolores abdominales han hecho claro que el parto ha comenzado, se manda a alguien de la familia a buscar al curandero (si es que se hace así), que llega a tomar el pulso, a vigilar el parto $y$ a rezar.

Primero calcula, por el pulso y la posición del sol cuál será el sexo del niño y a qué hora nacerá. En este momento, para apresurar el parto y ayudar, el curandero pone la punta calcinada y pulverizada de la cola de una zarigüeya (sne ${ }^{2} u \check{c}$ ) en una jícara llena de agua o de trago (poš), reza y le sopla y después se lo da a la mujer para que lo beba.

Algunas veces el polvo de cuernos de borrego recién quemados

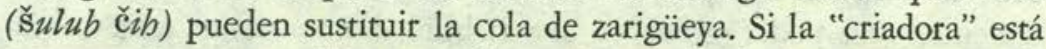
presente, hace una última prueba, para ver si el feto está colocado correctamente. Para facilitar más el parto, después de haber dado a beber a la mujer la cola de zarigüeya, el curandero coloca su cabeza junto a las asentaderas de la mujer sentada y sopla rítmicamente (ya yič tubtawaneb). Más tarde, si el parto es difícil, la mujer comerá un huevo crudo y/o se meterá una pluma de pollo a la boca varias veces. Mucho más eficaz es que un niño de seis o siete años se incline y golpee suavemente con su cabeza las asentaderas de la mujer, mientras dice 'awu, 'awu; se cree que así espantará al bebé fuera del vientre.

Cuando el nacimiento es inminente, la mujer se arrodilla o se pone en cuclillas con las piernas separadas y se coge de un soporte de la pared. Su esposo ayuda a mantenerla en esta posición asiéndola de las caderas. Nadie le oprime el estómago, uso común en otras comunidades de la región. Puesto que todos se quedan en casa durante el parto, algunas mujeres se sienten apenadas ( $y a$ šk'ešaw). Si una mujer se siente apenada por la presencia de los demás, puede salir ella sola para que su hijo nazca en algún arbusto cercano a la casa. Afuera la mujer se detendrá de un tronco. Si está adentro como es costumbre, se hincará sobre una chamarra vieja o algunas hojas de plátano secas que se habrán puesto en el suelo para recibir suavemente al bebé. La falda de la mujer queda tocando el suelo y en ningún momento se levanta. 


\section{Post-natal}

Cuando el niño cae ( $y$ a šp'ebkab 'alal), la madre se hace a un lado y es otra mujer quien recoge al bebé, pues la madre generalmente está muy débil. Si no hay nadie en la familia con experiencia suficiente para levantarlo, se pide a una mujer de otra familia que lo haga y que ayude a lavarlo y envolverlo con pañales. La madre se sienta entonces en una silla cerca del fuego y recibe al bebé para cargarlo. Estira entonces las piernas frente al fuego para apresurar la expulsión de la placenta. Cuando esto sucede, se enrolla firmemente un hilo alrededor del cordón umbilical cerca del abdomen del bebé. Se corta entonces el cordón a un palmo ( $h o b t$ ) de distancia del hilo, con un machete o con tijeras que están colocadas sobre una mazorca, y cuya punta ha sido esterilizada con fuego. Se tiene buen cuidado de no cortar el cordón demasiado corto, pues de acuerdo con la tradición esto provocaría que el niño no pudiera gritar fuertemente, y el poder gritar es una habilidad importante para comunicarse a través de los valles, en las veredas y entre las casas. El pedazo de cordón de $15 \mathrm{~cm}$. que le queda al bebé se envuelve con una tela que se amarra después. Se vigila frecuentemente y se suaviza periódicamente con una pomada (mentolato). Si se suaviza adecuadamente, el cordón se caerá en una semana, y si no tardará más tiempo. Una vez que se ha caído, el cordón de un niño se atará a la rama de un árbol con hilo, de modo que cuando crezca sea capaz de trepar alto, bien y sin miedo. Si se trata de una niña, su cordón se colocará debajo de una de las tres piedras del hogar (yoket), para que se convierta en una buena esposa y madre.

La placenta ( $m e^{2}$ ?alal) y el resto del cordón se ponen en las cenizas junto al fuego, como para que se sequen. La placenta se quema o entierra después al lado del fuego. Si no se hiciera de esta forma, el niño padecería dolores de estómago el resto de su vida. Sin embargo, antes de enterrar o quemar la placenta, el curandero examina las pequeñas protuberancias en el cordón umbilical, pues cada una significa otro niño que ha de nacer. Una protuberancia negra indica un niño, y una blanca una niña. Si las protuberancias están muy juntas, eso significa que los niños nacerán uno después del otro, uno cada año; las protuberancias más separadas indican más tiempo entre uno y otro.

Si el niño nace con una mancha mongólica (yašal yit) que cubre buena parte de su trasero, esto significa buena suerte para el futuro 
del niño. Cuando crezca, sus campos de maíz rendirán buenas cosechas. La explicación es que "se ha dado algo" al alma del niño (yič'obbe ta šč 'ulel bitik mayuk); en resumen, tiene buena mano para las plantas. Una mancha mongólica más pequeña significa que las cosechas serán menores. Si el niño nace con el cordón umbilical envuelto sobre los hombros y pecho, a manera de canana su destino será convertirse en asesino.

Un parto en posición pélvica es un claro indicio de que la madre morirá en el parto, y en tales circunstancias casi siempre sucede así. Si el niño ya ha salido, se enterrará a los dos en una misma tumba. Si éste todavía está adentro cuando la madre muere, no se retira para el entierro.

Una vez que se ha cortado el cordón, el niño recién nacido es bañado de pies a cabeza con agua tibia y raíz de amole (č'opak) después de lo cual se envuelve en un manto suave, alrededor del cual se sujeta ligeramente un cinturón blanco (sakil čubkilal). Mientras tanto se ha ayudado a la madre a amarrarse su faja firmemente alrededor del abdomen para impedir que le entre el frío (sik) a la matriz y evitar que se le haga barriga.

Ya que el niño está vestido, se le frotan los labios suavemente con el corazón de un chile (yat Pič). Después la madre mastica un poco de chile y pone una pequeña parte del chile ya masticado en la boca del niño. Hace esto para evitar que el niño crezca con frecuentes dolores estomacales. Se supone que el chile saca la "mala saliva" (sbolil ye - sbolil yo tan) de la boca del niño, saliva que podría causarle los dolores.

La madre da el pecho al niño inmediatamente, aunque algunas veces tiene dificultades, por no tener leche. En este caso el esposo debe ir a un río cercano y pescar algunas jaibas de agua dulce (nep'). La carne de las jaibas se cuece en una pequeña olla con poco chile, y se le da a la madre para estimular la producción de la leche. Se supone que el pollo también estimula la lactancia, y el día del parto sólo se permite a la madre comer pollo.

Poco después del parto se matan a dos pollos, un gallo y una gallina. Se da medio gallo al curandero y la familia se come lo demás. Si la familia es pobre, entonces solamente se mata a un gallo. Si no hay gallos, habrá que matar y comerse a una gallina. Es de gran importancia que la madre coma pollo en esta circunstancia. Además de estimular la lactancia, el pollo protege a su cuerpo débil de los efectos del "frío" que de otra forma entraría a su matriz y le impediría tener más familia. 
El día del nacimiento, toda la familia participa en la tarea de encontrar un nombre para el bebé, para lo que deben considerarse una serie de factores. Se tienen listos de cinco a diez posibles nombres para cada sexo, que se pueden combinar perfectamente con un apellido indígena dado.

De entre éstos, se escoge un nombre apropiado al sexo del bebé. La elección se limita aún más pues se excluye los nombres de los hermanos mayores. Si se trata de un niño, se piensa que el abuelo paterno debe tener a un niño que se llame como él y ocupe su lugar (shelol). Las niñas generalmente se llaman como sus abuelas paternas o tías.

Una vez que se ha decidido el nombre, se dicen "oraciones vitales" (sc'unobibal) ante el altar familiar (o una cruz en la casa), que consiste en una cruz de madera de pino sobre una base de madera, dos o tres ramas de pino enterradas en el piso junto a la cruz y agujas de pino esparcidas alrededor. Se queman velas e incienso y quien dice la plegaria, generalmente el curandero, emplea el nuevo nombre del niño para advertir a los dioses de lo que se trata. Las oraciones piden que el niño permanezca sano, que conserve su alma y lleve una vida próspera. Entonces se pega una poca de cera de abeja (čabek) en la coronilla del niño, para que los espíritus malignos (pukub) no lo molesten.

Esta cera se le queda pegada hasta que se cae por sí sola, lo que puede suceder hasta un año después. Otra salvaguardia que practican algunas familias es la de amarrar un poco de hilo azul (yašal na) alrededor del cuello del niño cuando tiene pocas semanas de nacido. Esto ayuda a evitar enfermedades.

Si el bebé se enferma a los dos o tres días de nacido, se deberá recuperar el alma en el lugar del nacimiento. Alguien que conozca el método apropiado debe quemar incienso frente a una cruz provisional de ramas de pino que se coloca en el lugar en que el niño cayó al suelo al nacer.

Después se dedican oraciones, y si la condición del niño es seria, se sacrifica un pollo del mismo sexo. Las oraciones ( $\check{a} a b)$ que se ofrecen piden al alma que regrese al niño y a la madre tierra que la libere.

Cuando un curandero llega para ayudar en el parto, atiende a la madre durante todo el tiempo necesario; raras veces se prolonga esta ayuda más de tres días. No recibe más paga que las comidas y el medio pollo que envuelve y se lleva a casa. Las comidas del curandero se distinguen en que siempre incluyen un huevo. 


\section{Restricciones a los padres}

Durante las primeras dos semanas después del parto, se supone que la madre y el niño deben permanecer en casa y evitar presentarse ante personas que no son parientes cercanos. La mayor parte de este tiempo, el niño está cubierto de pies a cabeza con un lienzo limpio. Si la mujer está en condiciones, será hasta después de dos semanas que puedan reanudarse las relaciones sexuales; después de veinte días no hay ya ninguna restricción.

Durante los veinte días siguientes al parto no se permite a la mujer bañarse. Se cree que si se bañara se le hincharía todo el cuerpo y se enfermaría. Tampoco debería trabajar en esos veinte días y si tiene que salir de la casa, no debería caminar mucho ni ir lejos, y debería usar su rebozo negro ('ibk'al coc) para evitar las enfermedades y que se le hinche el cuerpo.

También existen restricciones en cuanto a lo que la nueva madre puede comer durante esos veinte días. Todos los días debe tomar atole de maíz tibio ( $m a c^{\prime}$ ) con chile, para evitar que disminuya la leche para el bebé. Se le permite comer frijoles, tortillas y pollo, y si quiere, plátanos, aunque debe asarlos primero. Se debe calentar el agua antes de beberla. No puede comer carne de res, puerco o guajolote, ni huevos, tortillas tostadas, verduras crudas o frutas (excepto los plátanos asados), ni ninguna comida "fría".

Si una mujer saca a su niño afuera de la casa después de algunos meses de su nacimiento, debe cerrar la entrada a cualquier camino que corte la vereda por la que ella camina, con una o dos ramas. Esto se hace para que el alma del niño no escape, no se pierda y no vaya por el camino equivocado. Si perdiera su alma, el niño enfermaría y tal vez moriría. Si quiere cruzar el río o alguna corriente con su hijo, primero debe levantar tres piedras de la orilla y arrojarlas o llevarlas hasta la otra orilla. Esto permite al alma del niño atravesarlo. Si no se siguiera este procedimiento, el niño enfermaría de llorar continuamente. Existe un remedio para los casos en que el niño se enfermara por la incapacidad de la madre de cerrar una vereda o de cruzar el río con la ayuda de las piedras: se monta al niño en el lomo de un perro negro y se deja allí mientras la madre pronuncia la siguiente fórmula verbal: "Ve a buscar al niño donde fue abandonado, para que no llore mucho, ve a ver dónde se quedó" ( $b a$ 'ilatal te ?alale, banti č'ayem bilele, ma me nabtiluk te š'ok', ba 'ilatal te banti č'ay bilele). 
Un niño puede ser bañado cualquier día de la semana, pero no se le puede bañar en un río o corriente, ni con agua fría. El agua para bañar al bebé se calienta al fuego hasta que esté tibia. La madre, más que usar una tela, lava al niño con la mano. En lugar de jabón usa raíz de amole durante el primer año de vida del niño. $\mathrm{La}$ ropa del bebé sí se puede lavar con jabón, aunque no en el río, pues la corriente se llevaría la mugre y los deshechos de la ropa, lejos del hogar del niño. Si esto sucediera, el alma del niño se indispondría y esto causaría enfermedades. Tal prohibición implica una extensión conceptual del cuerpo humano que incluye alguno de sus productos y que parece tener una analogía en la costumbre del Pedrano (Tzotzil) de guardar restos de uñas y cabello (cf. Guiteras-Holmes, 1961: 113).

\section{Infancia}

\section{EDUCACIÓN DEL NIÑO}

La madre está cerca de su hijo en todo momento. Durante la mayor parte del día el niño está mamando, durmiendo en su regazo, en sus brazos o amarrado a su espalda. Generalmente se cuelga el largo rebozo de algodón sobre el hombro izquierdo de la madre y bajo su brazo derecho. Amarrado al frente, puede arrimarse de lado para que el niño pueda mamar a través de las aberturas laterales de su huipil. Algunas veces se coloca al niño, mientras duerme y por un rato corto, en la plataforma de la cama, lo que permite a la madre realizar algunas tareas dentro de la casa. Sin embargo, siempre lo está vigilando. De noche, el niño duerme a un lado de la madre mientras que su esposo duerme al otro.

A un mes de edad o más y mientras la madre está ocupada, el bebé puede ser cargado por un rato por un hermano mayor. Después de los cinco o seis meses, el bebé ya puede ser cargado en la espalda por una hermana mayor, que no tendrá más de siete u ocho años. Naturalmente, para entonces la hermana ya habrá aprendido la mayoría de las técnicas que usa la madre para calmar a un niño.

Hay un movimiento mecedor ( $y a$ ščipun - ya šč'awutes) que es característico de una mujer de pie que lleva al niño en la espalda. Con un pie detrás del otro, el peso del cuerpo se cambia de una pierna a otra con un movimiento mecedor ligeramente rítmico. Otra manera de calmar a un niño o de hacerlo dormir es golpeando suavemente su espalda o sus sienes al tiempo que se entona suavemente šššš. En Cahalč'en, un método muy común para calmar a un niño es tocarle los genitales, aunque esta práctica no es tan común en Mahosik'. 
Se da el pecho al niño cuando éste tiene hambre, sin tratar de establecer ningún horario. El niño mama hasta que tiene tres o más años, a menos que un nuevo embarazo impida la lactancia. Por lo general, se permite que un niño mame durante los tres primeros meses del nuevo embarazo de la madre, pues después la leche se echa a perder. En ocasiones, algunos niños podrán mamar hasta el cuarto o quinto año. Durante el primer medio año de vida del niño, se le darán pequeñas cantidades de atole de maíz y más tarde se le permitirá masticar y chupar pedazos de tortilla, mango, naranja y plátano. $\mathrm{Al}$ año, el niño puede complementar su alimentación con cualquier alimento que los adultos coman.

Mucho antes de que el niño pueda hablar, se ofrecen respuestas verbales a sus movimientos, gestos y sonidos. La madre tomará algo de comida y otros objetos cercanos, que ofrecerá al niño diciendo: "¿quieres esta naranja, esta tortilla, o qué tal un plátano?", etcétera. Estas propuestas se hacen primero para calmar los deseos del alma del niño. Se cree que si no se ofrece comida al niño, el alma puede abandonar su cuerpo para ir a buscar lo que quiere, haciendo que el niño se enferme y quizá muera. Cuando un niño se enferma y el curandero viene a tomarle el pulso y a adivinar la causa, una de sus preguntas a la madre es que si ha ido hace poco al mercado (donde el alma del niño puede haber desaparecido para ir a comer algo). Conocer la respuesta a ésta y otras preguntas, le ayudará a diagnosticar la enfermedad y a seleccionar las plegarias adecuadas.

Desde el principio una niña lleva un huipil hecho en el lugar, o una camisa de algodón hecha por los ladinos, una falda azul como la que usan las mujeres adultas y un ancho cinturón blanco, más suave que el rojo que se agrega a su guardarropa algunos meses más tarde. El huipil, la falda y los dos cinturones - el blanco se usa sobre el rojo- es el atuendo común para las mujeres de cualquier edad. Un niño usará una larga camisa de algodón, que se puede ajustar a la cintura con una versión miniatura de la banda larga que usan los hombres. Una vez que el niño pueda caminar, se le dejará andar desnudo o sólo con una camiseta hecha por los ladinos, hasta que tenga tres o cuatro años. Las familias que se lo pueden permitir, compran a sus hijos su primera chamarra cuando tienen dos años y medio o tres. Antes de que reciban su primera chamarra, algunos niños usan un pequeño vestido blanco de algodón cosido al dobladillo de la camiseta o de un suéter, que generalmente no se faja. Este tipo de vestido recibe el mismo nombre que la falda que usan las mujeres (cekel). No es sino hasta que tiene siete $\mathrm{u}$ ocho años que 
el niño recibe su primer par de pantalones cortos (wešal), que usa debajo de la chamarra.

Al principio, la mayoría de los niños usan pañales de un tipo; unos durante los primeros cuatro o cinco meses y los otros hasta que aprenden a caminar. Estos pañales consisten en un lienzo largo, envuelto como una falda y uno más pequeño entre las entrepiernas y que es sostenido por el más grande. Cuando va a cambiar los pañales y especialmente si el niño está llorando, la madre ve si hay heces y orines; el excremento se retira con la mano, que después se limpia con un pedazo seco del mismo pañal. Éste se lava con agua caliente y se cuelga para que se seque. Antes de usar un pañal limpio, siempre se calienta por unos minutos. Se enseña al niño a avisar de sus necesidades, cuando ya sabe caminar. Primero aprende a avisar, aunque todavía no sepa hablar, a un hermano o padre y se le castiga levemente si orina su ropa u obra dentro de la casa sin avisar. A la edad de dos años se espera que la mayoría de los niños puedan controlar la vejiga y los intestinos, aunque un niño de esta edad bien puede orinar en el momento o lugar menos indicado, lo que provoca risa más que un regaño. Mojar la cama después de los tres o cuatro años, da lugar a ligeras burlas. El niño que cometió la falta oye comentarios como éstos: "¿Por qué te orinas? ¿Eres todavía un bebé? ¡No debieras orinarte así!” ( $b i$ yu’ un ya šč $u$ šnat, ya bal 'alalat to. ma štun ya šč $u$ šnat). También es posible -aunque mucho más raro- que el niño sea castigado con una cachetada, con nalgadas que se le pueden dar con la mano o con un cinturón o con un golpe de vara en la cabeza. Existe un remedio para que un niño no vuelva a mojarse en la cama. La madre recoge con los dedos el jugo resinoso que sale del extremo de un palo de acacia o de roble fresco ardiendo y lo aplica tres veces consecutivas al pene del niño (ste? el yat). Este remedio no se usa nunca con niñas (cf. Redfield y Villa Rojas, 1962: 190, fn.).

Las funciones corporales no son en sí fuente de vergüenza en Tenejapa. En la familia se discuten con relativa libertad, sin ninguna restricción aparente de edad o sexo. Las pequeñas aprenden, por instrucción e imitación, a orinar en cuclillas a la orilla del camino, o los arbustos, sin levantar la falda o ensuciarla. Cuando un niño recibe su primer par de pantalones cortos tejidos sabe, por haberlo visto antes, que debe volverse y levantar la pierna derecha del pantalón para no mojarla. Después de los cuatro o cinco años es deseable un cierto aislamiento y mucho más después de la pubertad, pero el ser visto accidentalmente, casi nunca causa vergüenza. 


\section{Crecimiento y fórmulas para desarrollar la babilidad}

Para los padres es de interés el crecimiento de sus hijos y su desarrollo en actividades específicas. Para estimular tanto el crecimiento como el desarrollo, se cuenta con algunas técnicas. Cuando un niño tiene más de ocho meses y está cerca de los tres años, la madre levantará un elote hasta la cara del niño tres veces, pronunciando a la vez la palabra č $i a$ (" $¡$ crece!"). A continuación el niño come el maíz y se supone que deberá crecer bien y rápido, al igual que la buena semilla. Una madre consciente repite este procedimiento dos o tres veces al año.

Para que un niño pueda crecer fuerte y sano, se debe guardar en una caja algo de su cabello y uñas hasta que tenga tres años.

Se cree que si una madre poco cuidadosa los tirara antes, el alma del niño se inquietaría por la pérdida y esto provocaría una enfermedad en el niño. Sin embargo, parece que no se encuentra ni en las uñas ni en el pelo parte alguna del alma humana.

El primer corte de cabello (hošel shol) del niño es importante para su desarrollo, aunque no puede hacérsele cuando es muy pequeño todavía. Debe haber cumplido un año o quizá dos. Antes de ese día se le puede arreglar (setel sba) el cabello del frente para impedir que le cubra los ojos, pero eso es todo. Si se le corta demasiado pronto, se dice que su alma le sería quitada y que rodaría por las montañas ( ya lab yič' celk' unel ta wic ta čen šč'ulel), lo que causaría que enfermara el niño. El primer corte de cabello significa que al menos se le cortará todo el cabello de la nuca. Se deja a la discreción de la madre raparle o no toda la cabeza. El corte se hace en la mañana; generalmente lo hace una parienta de edad que tenga experiencia. Esa tarde se realiza el ritual norep. La mujer toma un pedazo de carbón de leña (de preferencia de pino) y traza una línea de la mitad de la nariz del niño hasta la coronilla y después traza un círculo alrededor de su cabeza, arriba de las orejas y dice norep, ma me šč'ayat ta wic ta č'en; norep norep, ma me šč'ayat ta wic ta čen; norep norep. . ., una fórmula que debería impedir que se enfermase el niño. El corte de cabello y el ritual norep se repiten algunas veces más durante el crecimiento del niño. Una vez que el niño ha alcanzado la edad de ocho o nueve años, este ritual ya no es necesario.

Cuando un niño cumple cinco años se emplea la técnica de (č'uyel), colgarlo, para que se vuelva más alto y más activo. Temprano en 
la mañana, a la hora en que sale el sol, se sostiene al niño ante un árbol alto para que cogido de una rama alta del mismo, se cuelgue de las manos por algunos minutos. Una vez que el niño conoce la técnica, la madre puede decirle simplemente que "vaya y cuelgue", lo que hace con cierta frecuencia hasta que el niño tenga nueve años. Se cree que si no realiza este ejercicio se volvería flojo (barakan) y chaparro (komol).

Cuando se dispone de huevos, los niños comerán uno diariamente hasta que tengan siete $\mathrm{u}$ ocho años, como auxiliar para la buena salud y el crecimiento rápido. Para los adultos, los huevos son un lujo, los comen sólo en raras ocasiones, por ejemplo, cuando reciben a algún huésped importante. Los huevos también desempeñan un importante papel cuando el niño aprende a caminar. Cuando el bebé logra ponerse de pie, no importa si está muy inseguro, y comienza

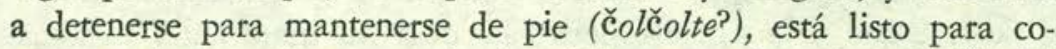
menzar el tratamiento con la "medicina para las piernas" (špošil 'akanil). Cada vez que la madre parta un huevo para comerlo, tomará un poco de la clara que queda en el interior y la aplicará con el dedo a la articulación de la rodilla y al tobillo. Se puede aplicar también al tendón de Aquiles y en la parte superior del pie. Se supone que esto acelera el aprendizaje del niño (es decir, el ritual permite al niño imitar al pollo que camina desde que nace). Si el niño ya camina, esto le ayudará a hacerlo con mayor rapidez. El uso de la clara es también un remedio para el niño que cae con frecuencia. Estas aplicaciones continúan hasta que el niño tiene tres o cuatro años y ya no cae con frecuencia. Se dice que sin la ayuda de la clara el niño sería excesivamente lento en su aprendizaje, sus músculos no serían fuertes y se caería de boca completamente extendido (pakal k'iyil) cuando tratara de caminar.

Aunque se puede cargar al niño en "cabestrillo" ( $s i b c$ ') en la espalda, hasta que tiene cuatro o cinco años, esta costumbre se empieza a dejar una vez que el niño aprende a caminar. Ya que no hay ningún medio de transporte en Tenejapa y todo se hace a pie, es importante que niños y niñas aprendan pronto a caminar. Cuando un niño está aprendiendo a caminar, la madre lo toma de las manos para ayudarlo a caminar alrededor de la casa tres veces. Esto debe hacerse en la mañana: hacerlo en la tarde solamente retrasaría el crecimiento del niño. Al principio la madre camina de espaldas y jala al niño. Al progresar el niño, cuando ya es capaz de caminar solo, se le da una vara para que se apoye. El circuito alrededor de la casa debe hacerse tres veces y si el niño se cansa después de la primera 
vuelta, se le permite descansar un poco antes de continuar. Si él da varias vueltas a la casa en la mañana, se dice que aprenderá a caminar rápidamente.

Una vez que el niño ha aprendido a caminar e insiste en acompañar a su mamá a un corto paseo y a medio camino decide que quiere ser cargado, la madre cortará una rama chica de la tradescantia o alguna otra y le pegará en los tobillos (ya yak'be wab̌ - ya shisbe c'eman ta yakan), para que el niño no se canse y no llore.

Hablar bien, con juicio y prudencia, es una habilidad que se admira en Tenejapa, y los padres admiran esta habilidad tanto en sus hijos como en otros niños. Para apresurar el desarrollo de las habilidades verbales del niño, se cree que es útil que la madre golpee suavemente la coronilla del niño de vez en cuando (tal vez una vez al mes) con un calabazo (culha), de los que se usan para guardar las tortillas calientes. Este tipo de tratamiento comienza cuando el niño tiene un año y medio o dos y termina cuando ya sabe hablar. Un procedimiento similar, utiliza una pequeña campana (kaškawuela) como la que utiliza el alférez, para lograr el mismo efecto. Se toca levemente la cabeza del niño con la campana tres veces y tres veces el pecho. Se cree que un niño cuando aprende a hablar está imitando a la calabaza y a la campanilla que también "hablan".

A un niño que tarda en aprender a hablar, que no dice nada cuando podría hacerlo, o que tiene dificultades de pronunciación, se le pueden dar una o varias cigarras (čikitin) asadas a comer. La cigarra "habla mucho" (lom šk'opoh) y al comerla se da la posibilidad al niño de copiar esta habilidad. El uso de la campana como lo describí antes, es también un remedio para el retraso al hablar. No se cree que la campana ni la cigarra sean de utilidad en casos de tartamudos o mudos. Se dice que estos dos defectos acompañan a la persona durante toda la vida y que no hay remedio para ellos.

El niño no recibe ninguna educación formal en el lenguaje antes de ir a la escuela. En caso de que se le mande a la escuela, será cuando el niño tenga seis años o más. En ese momento se le enseña español. Por otra parte, los padres y los hermanos mayores corrigen ocasionalmente errores fonológicos y gramaticales de los niños cuando éstos tienen de dos años y medio a cuatro. Es más frecuente que se imiten los errores a que se corrijan, aunque con frecuencia simplemente se ignoran. Del mismo modo es más frecuente que se hagan burlas de errores en el uso del lenguaje, a que se corrijan.

El uso del lenguaje a que nos referimos aquí, se refiere a los patrones de la conducta del lenguaje que se manifiestan en la forma 
de rutinas tales como saludos, modos de iniciar y terminar conversaciones, despedidas, insultos y respuestas, citas, relatos, disculpas, agradecimientos, brindis, etcétera, tanto como reglas para interrupciones, guardar silencio, etcétera. Existe en Tenejapa un complicado sistema de saludo que parece depender del sexo, edad y situación, con complicaciones extras debidas al status y a la hora del día. Aparentemente no se enseña a los niños el uso apropiado de las formas de saludo y es raro que a la edad de seis años apliquen lo que saben. El tzeltal también tiene una buena cantidad de partículas adverbiales como bič ('así') que, si la usa uno de los que participa en el diálogo, obliga a quien lo escucha a emplear las partículas correspondientes para urgir al que habla a continuar. La regla es bastante sencilla aunque no es expresable para un nativo, y no se enseña a los niños ni formal ni informalmente a usarlas. Sin embargo, hay otros aspectos del uso del lenguaje que sí se explican a los niños.

Una vez que el niño puede participar en conversaciones comprensibles con sus parientes, comienza a escuchar lo valioso que es para sus padres el uso del lenguaje, algunas veces directamente, otras por burlas y risas, y otras más por dichos, relatos tradicionales con moralejas o habladurías. El niño aprende a no hablar demasiado o muy fuerte, especialmente de noche, y que no es bueno interrumpir a alguien cuando habla. Aprende que debe responder a las preguntas que le hagan los adultos, especialmente si son personas de edad. Aprende que entre los varios tipos de habla estúpida o mala (čopol k'op) se encuentran el jactarse (erinka k'op - buirio k'op), hablar a espaldas de los demás (walak' pat k'op), romper promesas (subtem $\left.k^{\prime} \circ p\right)$ y dar a conocer conversaciones que se llegaron a oír $\left({ }^{2} a^{2} y\right.$ stohol k'op), mientras que hablar bien (rason k'op) es hacerlo con elocuencia y profundidad, con buenas ideas, lenta y deliberadamente, como lo hacen los hombres de edad. Los padres castigan a los niños chicos por mentir, gemir, gritar, insultar, pero no los premian porque hablen bien. Por otra parte, mientras un niño aprende a hablar, las amonestaciones son suaves y más amables que secas. Es de gran importancia que un niño aprenda a hablar respetuosamente a otras personas, lo que se le dice infinidad de veces mientras crece. Gran parte del habla respetuosa está en el tono de la voz. Entre las mujeres la voz de respeto es de falsete (sc'ulet) y quejumbrosa. Es mucho más notoria cuando habla con un hombre extraño y menos cuando habla con una mujer de su edad. Entre los hombres, la voz ideal o de respeto es alta y fina (č'in $m u k$ ', literalmente 'garganta diminuta') y tal vez con algo de gemido. Se oye ante todo cuando un hombre 
joven habla con uno mayor que tiene un cargo y le pide un favor. Mientras más pronto aprenda un niño a hablar respetuosamente a cualquier persona, especialmente a aquellas de edad, tendrá menos posibilidades de incurrir en la ira del alma de esa persona. A la edad de cuatro o cinco años, la mayoría de los niños emplean ya la voz de respeto con adolescentes y adultos, aunque no con otros niños.

Los tenejapeños están de acuerdo en que las niñas aprenden a hablar con mayor facilidad que los niños, y es cierto que los niños crecen más lentamente que las niñas también en otros aspectos. Las niñas caminan con mayor rapidez, les salen los dientes antes y alcanzan antes su estatura media. Dicen que esto se debe al hecho de que los niños tienen que hacer contribuciones ( $y a$ yak' stobomabel), a la casa y a la comunidad y que por eso no quieren crecer. Retrasan su crecimiento para aplazar "el pago de sus cuotas". Y las niñas se van para arriba porque no tienen responsabilidades que afrontar, dicen.

\section{Sueños}

Los tenejapeños creen que la salud de un niño puede verse afectada por los sueños de sus padres, aunque la dirección de la causalidad no está clara del todo. Claramente se reduce el elemento volitivo de parte del que sueña, mientras que se da una gran importancia al valor de pronóstico, siempre que los símbolos puedan ser interpretados correctamente. Algunas interpretaciones simbólicas se conocen generalmente, pero en muchos sueños se debe consultar a una persona de edad que sepa, para descubrir el significado de ciertos augurios e indicadores. Por lo general se acepta que el alma de una niña puede estar simbolizada por ropa femenina, por una canasta (moč) o por una jícara (bobč). El alma de un niño puede aparecer en los sueños como dinero ( $t a k^{\prime}$ in) o como prendas de vestir masculinas.

Un niño morirá si uno de sus padres sueña que la ropa del niño es robada por un animal o arrastrada por la corriente de un río. Si en el sueño el animal se come la ropa del niño, éste enfermará. Si sueñan que una canasta o una jícara flota corriente abajo en un río, una de las hijas del matrimonio morirá. Si por el contrario se trata de un niño, los padres sueñan que una persona llegará a la casa a pedir dinero y se lo llevará. Si sueñan que un mestizo se lleva una camisa o un huipil un niño o una niña, según el caso, morirá. 
Si el sueño ocurre temprano, antes de medianoche, pasarán seis meses o más para que la muerte ocurra, pero si se sueña en la madrugada, entre las tres y las cinco de la madrugada, la muerte ocurrirá pronto. Dormir con la cabeza en dirección al poniente, se supone que causa pesadillas; para tener bueños sueños, hay que dormir con la cabeza en dirección al oriente. En caso de que uno de los padres haya tenido un mal sueño que presagie enfermedad o muerte a uno de sus niños, al amanecer la madre rezará para evitar el peligro anticipado, "cubriendo el sueño" (makel wayič) con la oración. De cualquier manera, es frecuente que la enfermedad o la muerte llegue al niño.

Se cree que los niños no sueñan sino hasta que tienen seis años. Una niña huerfana de ocho años de edad, que vivía con la familia de mi ayudante, soñó una noche que estaba acostada boca arriba y que unas briznas de pino ardían cerca de su cabeza, símbolo de la muerte propia e inminente. En la mañana, la niña se lo contó a su madrastra para que pudiera rezar. Todos en la casa estaban alarmados. Seis meses después, la niña murió.

\section{Probibiciones a los padres}

Los padres deben ser muy cuidadosos para no hacer cosas que puedan afectar desfavorablemente a sus hijos. La madre que corta una vara para pegarle a su hijo en los tobillos, debe cuidarse de coger una rama del takin č́iel (Despodium sp.), puesto que si se pega a un niño con esta vara, éste dejará de comer, adelgazará y podrá enfermar y hasta morir. Además no es bueno dejar una silla o banca desocupada en el centro del cuarto. Si la banca no se usa, deberá ponerse derecha, recargada contra un poste o la pared, especialmente de noche. Además de invitar la visita de un mal espíritu (pukub), seguir esta costumbre afectaría a uno de los niños de la familia, retardando su aprendizaje a caminar. Otra prohibición se refiere a la hierba sot čan wamal (Crotalaria maypurensis, HBK), con sus vainas con semillas como matracas. Se dice que si se juega con la planta, agitando las vainas con las semillas, entonces los hijos comenzarán a llorar continuamente. Algunos niños de cinco o seis años son capaces hasta de identificar esta creencia con la planta, lo que indica un temprano aprendizaje de este conocimiento de las plantas.

Falta de precaución por parte de los padres puede provocar una serie de efectos en sus hijos, por ejemplo, la calvicie. Mientras se 
limpia la milpa la persona debe estar segura de dejar completamente limpias las tres raíces en las que estaba trabajando al terminar el día. De no hacerlo así sus hijos crecerán con amplias entradas laterales en la cabeza (shak'am), un rasgo indeseable. Una

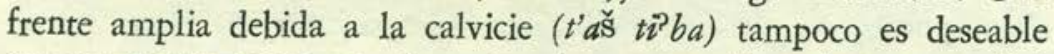
aunque es un rasgo común entre los mayas de ambos sexos (cf. Redfield y Villa Rojas, 1962:182). Si las tres piedras del hogar se dejan en un círculo muy amplio, entonces los niños de esa familia podrán tener cabezas grandes, altas y feas, puesto que el cabello no crecerá en ellas. Esta misma calvicie afectará a los hijos si, habiendo limpiado la ceniza para tostar los chiles, se deja limpio el espacio después de tostar y guardar los chiles.

Algunas restricciones respecto al comportamiento de los padres se refieren a defectos de nacimiento y a la cantidad de hijos que se tendrán. Si hay luna llena y luz suficiente para ver bien con ella, una persona no debería salir llevando teas de pino, o sus hijos pueden nacer ciegos o con algún otro defecto de esa naturaleza. Pero si no hay luna y se necesitan teas de pino para alumbrar el camino en la noche, es mejor llevar tres o cuatro por lo menos, para asegurarse de que no se tendrá solamente un hijo.

\section{Probibiciones a los niños y remedios}

En Tenejapa la salud y la vida misma de una persona dependen fuertemente de su alma (čulel), y en forma menos directa de la suerte del animal que es su doble (labil). Mientras que los dobles o naguales de todos los tenejapeños viven juntos en un corral en Palenque (palenka č'en'ak'obana) y es muy poco lo que se puede hacer para proteger al suyo, el alma reside dentro del individuo y se pueden hacer muchas cosas para protegerla del mal, aunque no siempre satisfactoriamente. Cosas como caídas, golpes, gran tristeza, llorar, miedo, exponerse al agua, el frío (sik), el aire ( $i k$ ), o la envidia de otros deben evitarse, pues pueden llevar a la enfermedad y finalmente a la muerte (lingüísticamente, 'enfermedad' y 'muerte' tienen el mismo radical, čam, y se cree que la enfermedad es un estado conceptualizado de la muerte, cuya conclusión lógica es la muerte misma). Estas cosas son peligrosas para el individuo, ante todo por sus efectos sobre el alma que podría perderse a resultas de cualquiera de estas circunstancias, especialmente si se trata de un niño. 
Mientras más chico es el niño, más débil (k'un) y caprichosa, más fácil de herir y de perder será su alma. Aunque las caídas son potencialmente peligrosas para personas de todas las edades, se cree que un niño es especialmente susceptible a los peligros que lo acechan, porque su alma es débil. Un niño chico que se cae puede perder su alma a favor de la tierra. Es por eso que cuando un niño está aprendiendo a caminar y se levanta tratando de dar algunos pasos, sus parientes se apresuran a sostenerlo para que no caiga. Una vez que sabe caminar se le permite acompañar a su madre cuando va a coger agua al río o a la fuente. Si el niño tiene tres años o es más chico y cae en la vereda, la madre casi siempre se preocupa mucho por su alma. Puede pensar que su alma se perdió y pasó a la tierra y que es mejor rezar para que la recupere en ese lugar $\mathrm{y}$ en ese instante, y no esperar a que el niño enferme. Para hacerlo trae tres ramas de pino que clava en el suelo al lado de la vereda donde ocurrió la caída. Mientras reza frente a este altar provisional, retuerce el cuello de un pollo y pide a la tierra que libere el alma de su hijo a cambio de la del pollo; un gallo si se trata de un niño y una gallina si es una niña. Encaja dos manojos de plumas, tres en cada manojo, en el suelo frente a las ramas de pino; enciende trece velas frente a las plumas y quema trece pedazos de incienso de copal (pom) frente a las velas. Si la madre no considera que la caída fue seria, o si se trata de un niño mayor, puede esperar a la mañana siguiente para rezar en casa por la salud del niño, o bien puede esperar hasta que el niño enferme, para rezar en casa, donde cayó el niño o en alguno de los promontorios cercanos. Puede ser que hasta llame a un curandero que le ayude a rezar.

Algunos peligros pueden alejarse con unas pizcas de tabaco (bankilal may) envueltas en un paquete de cáscara de maíz que se usa debajo del cinturón, en la espalda. Los niños usan estos paquetes de tabaco cuando están enfermos o se están recuperando. Tanto los adultos como los niños llevan tabaco a los velorios. En presencia de la muerte se usan las bolsitas de tabaco debajo del cinturón o en la parte posterior del cuello. Algunas veces se aplican las cenizas del tabaco a las rodillas y articulaciones para mayor protección. El tabaco protege también contra los rayos. En todos los casos funciona además, para impedir que el alma sea atacada por fuerzas externas.

Demasiado llorar o una gran tristeza pueden ser dañinas para un niño, pues el alma puede trastornarse o hasta ser llevada lejos. 
Es por eso que los padres casi siempre acceden a las peticiones de un niño persistente, que desea algo ardientemente, tanto como para amenazar con llorar. Otra forma de calmar a un niño que quiere llorar es dormirlo. Si las técnicas para tranquilizarlo no dan resultado, se puede colocar un gran escarabajo con pintas negras y blancas (wayway čan) en la faja del niño. Generalmente el escarabajo saldrá de la faja en una hora, pero para entonces debería haber logrado hacer domir al niño. Se dice de un niño que llora continuamente cuando su madre se embaraza otra vez, que está celoso del niño que aún no ha nacido. Un remedio para esta clase de llanto es frotar bayas de saúco (čîilte? Sambucus mexicana Presl.) en las asentaderas del niño durante tres mañanas consecutivas.

Un susto repentino a un niño pequeño podría hacer que perdiera su alma, de modo que se evitan situaciones que pudieran espantar al niño o a su alma, aunque no siempre es posible prevenirlas. Si la enfermedad de un niño se diagnostica como debida a un susto (šivel), se cortan tiras de las hojas del pošil šinel (Phylantbus nouriri), una planta pequeña, semejante a la mimosa; se ponen en agua en una jícara y se lavan con ella los brazos, espalda y estómago del niño.

El alma o parte de ella se puede quitar a un niño si se hace una copia de él o de su voz. Se dice que la copia contiene parte de él. Si la copia del niño se lleva lejos, se dice que la parte del alma que se dejó atrás llorará por el resto o tal vez irá en su busca. Varias veces se me negó el permiso de fotografiar o grabar la voz de un niño pequeño, porque la madre pensó que me llevaría la copia, lo que causaría que el niño enfermara o muriera.

Bastante tiempo antes de los seis años un niño ha aprendido ya a respetar a sus mayores, a dejarlos pasar en el camino, dejarlos entrar primero en la casa, obedecer sus deseos; a no molestarlos durante la comida, etcétera. Esto se debe sobre todo a que el alma de una persona grande es superior (lom toyem) y muy fuerte (lom tulan), mientras que la de un niño es muy débil, maleable y suave (lom k'un). Si un niño se mostrara irrespetuoso con una persona grande, si pasara por ejemplo corriendo a su lado, mientras ésta se encuentra sentada, comiendo junto al fuego, es posible que esta persona o su alma se enojará tanto que pudiera importunar al alma tierna del niño. Hasta un pariente cercano y bien relacionado puede ser peligroso al niño. De hecho un pariente que se está muriendo es más peligroso que un desconocido. El padre de mi ayudante había estado muriendo lentamente de cáncer por poco menos de un año, 
y su condición fue empeorando rápidamente poco después de mi llegada al lugar. En esta misma época su nieto de ocho años murió repentinamente y sin motivo aparente. A los pocos días, la salud del anciano comenzó a mejorar. La explicación que la familia dio de este cambio repentino, fue que el alma del anciano, en una lucha desesperada por sobrevivir en este mundo, tomó la esencia de la vida de su pariente cercano, cuya alma estaba débil debido a su juventud, para ganar unos preciosos días o meses de vida. Estos "robos de almas" se cree que ocurren más frecuentemente dentro de las familias que entre ellas.

Dado que los mayores son tan poderosos de alma, generalmente se les trata bien cuando visitan a los parientes. Se cree que si no los tratan así, su alma se ofendería y causaría mal a uno de los niños de la casa. Por razones semejantes, se enseña siempre a los niños a saludar a las personas mayores que pasan por el camino o cerca de la casa. Si no se oye el saludo, se espera que el niño lo repetirá más fuertemente para evitar el enojo del alma de la persona de edad.

Cuando el niño es todavía pequeño, de un año aproximadamente, se piensa que es peligroso para la madre permitir que el niño chupe su dedo pulgar. Cuando la madre ve a su hijo chupándose el pulgar o el puño, debe sacarle el dedo de la boca inmediatamente, para impedir que se le caiga el cabello (a ella). Cuando el niño es mayor, como de año y medio, ya no es peligroso para la madre que el niño se chupe los dedos o el puño, pero no le permite hacerlo, pues se cree que esto le agranda la boca al niño o se la empuja hacia afuera como en una mueca constante $(t u b t \vec{i})$.

Una vez que el niño tiene la edad suficiente para salir un poco de la casa, comienza a aprender que algunas plantas le son perjudiciales. Aprende a identificarlas por la vista, al mismo tiempo que escucha sus nombres. Una variedad del quiebracajetes (yas̆al $n i c ̌$ čin?ak) (Ipomea sp.) se cree que causa granos enterrados en las orejas de los niños que juegan con ella. Se supone que los niños tampoco deben jugar con las vainas del petu mas (especie de frijol silvestre no identificada), pues esto les causaría enormes círculos negros en cualquiera de las asentaderas. Se dice a los niños que no deben jugar con la cola de caballo (tubt) (Equisetum myriochaetum) o su pelo pubiano crecerá muy largo, tanto como los pelos de la planta. Tampoco deberá jugar con bellotas (sit bibte?) o con huesos de aguacate ( $b a k^{\prime}$ on), pues esto podría causar que le salieran tumores (čakal) en sus cuerpos. Ningún niño en Tenejapa 
debería masticar madera de pino, especialmente pino tea (cabal tah), pues esto haría que pronto perdieran sus dientes.

Los niños descubren que tampoco pueden comer nada que haya sido mordisqueado por ratas o ratones, ni fruta que haya sido picada por los pájaros. Hasta los jóvenes evitan estas comidas, pues algo que ha sido mordisqueado por una rata, está sucio y puede causar enfermedades, mientras que si come la fruta picada por los pájaros, podría ser acusado por los vecinos de hechos malos, tales como asesinato, robo o fornicación. Solamente las personas muy ancianas pueden comer estos alimentos contaminados, y eso solamente después de cortarles la parte mordisqueada y de pronunciar una fórmula verbal para contrarrestar sus efectos.

A los niños como de dos años y medio, se les advierte que no pueden comer dulces si tienen tos, que no pueden comer ni beber atole de maíz si están de pie, y que es malo comer con la cabeza echada hacia atrás (bawal). A algunos hasta se les dice la razón de algunas de estas prohibiciones. Se dice que comer de pie podría causar que llegara el viento y arruinara su milpa a medio crecer. Comer con la cabeza echada hacia atrás hace que les salgan muchos granos (wabbab) en la cara.

A los niños a quienes se ve poner los pies en una de las piedras del fogón, se les regaña y se les dice que eso podría hacer que se volvieran flojos y estúpidos. Algunas otras travesuras en casa, por ejemplo intranquilidad, jugar con la comida, ensuciarse, jugar con los utensilios de la cocina, jugar en la chimenea, etcétera, causan regaños, pero no se asocian con historias de peligro potencial para los niños.

Una vez que un niño comienza a jugar afuera, se le advierte que no entre en cavernas ni agujeros de desagüe, pues podría perder fácilmente su alma en estos lugares. Son la entrada a la morada del "dios de la naturaleza" (btatik 'ánhel). Se les advierte también que no arrojen piedras a los colibríes que están chupando la miel de las flores: el hacerlo provocaría que los utensilios de metal en la casa del que lo hubiera hecho, perdieran su filo y temple, y que se rompieran en cuanto los usaran.

A los niños que uno se encuentra gritando, alborotando o jugando de algún otro modo, pero haciendo mucho ruido, se les puede castigar y contar la historia de los niños y el petate. Hace tiempo, según cuenta la historia, había muchos niños que hacían demasiado ruido en sus juegos irrefrenables. Un mal espíritu (pukub), con apariencia de hombre, se acercó a los niños atraído por el ruido 
que hacían y les preguntó qué estaban haciendo. Los niños huyeron atemorizados y se escondieron en un petate que enrollaron a su alrededor. Se ahogaron y murieron juntos en el petate enrollado, todo por estar jugando con mucho alboroto y haciendo demasiado ruido.

Hacer ruido de noche es considerado aún más peligroso para los niños, porque los espíritus malignos (pukub) son atraídos muy fácilmente de noche y pueden causar una enfermedad o la muerte si se les da la oportunidad. En Tenejapa hay que ser especialmente cuidadoso, no sólo en lo que se refiere a los ruidos. Diversos males acechan en las veredas fuera de la casa. Se supone que los niños de ocho o nueve años no deben salir de la casa solos en la noche, pues esto podría significar que se busca a la enfermedad. Algunos hasta dicen que un niño no debe buscar en las veredas si un ruido sale de allí, en el atardecer. Podría ser un espíritu malo el que estuviera haciendo los ruidos, y el niño al verlo, moriría. Se dice a los niños que no tiren agua o basura fuera de la casa en la noche, pues los dioses ancestrales podrían estar esperando allí. Se dice que aunque los dioses ancestrales no estuvieran allí afuera, aquel que tire basura en la noche, huirá compulsivamente de su casa ( $y a$ šlok' ta 'anel) y nunca regresará. En la noche no deberían pronunciarse los nombres de los niños: malos espíritus podrían oírlos y molestar a los niños (cf. Johnson, 1939: 137). Así, especialmente de noche, los familiares se refieren a los niños como tatil ('niño pequeño') o kancil ('niña pequeña').

En Tenejapa la posición normal para dormir, tanto para niños como para adultos, es de lado. Si a un adulto le duele el estómago, puede decidir dormir sobre él. Un niño no puede hacerlo, especialmente si es muy chico, pues se cree pudiera sofocarse. Ni los adultos ni los niños debieran dormir sobre la espalda, pues hacerlo así sería invitar a un mal espíritu a venir y sentarse a horcajadas sobre el corazón ('o?tan), causando una enfermedad.

Jugando, un niño podría tratar de ponerse la ropa de un hermano mayor. La madre cuidadosa interrumpirá este juego inmediatamente. Se cree que si un niño menor usa la ropa de su hermano mayor, éste dejará de crecer hasta que el chico lo/la alcance en estatura.

En muchas saciedades es costumbre que los niños se burlen de otros niños o hasta de los adultos. Se advierte a los niños tenejapeños a quienes uno se encuentra burlándose de alguien que es paralítico, jorobado, que tiene labio leporino, o algún otro defecto físico, que el niño que se burla de una persona enferma, puede ser 
atacado por ese mal. Los informantes dicen que la mayoría de los padres consideran difícil que un niño pueda desarrollar los síntomas de que se hace burla, pero es posible.

\section{Disciplina}

Los padres no confían en el deseo del niño de conservarse sano y a salvo del peligro como único incentivo para su buen comportamiento. Generalmente un niño es muy pequeño para comprender las consecuencias de sus actos antes de los seis o siete años, así que los padres recurren a amenazas más inmediatas, a promesas de premios y algunas veces al castigo corporal.

Para un norteamericano los padres tenejapeños parecen ser muy pacientes e indulgentes con los niños que se portan mal, especialmente cuando la salud o la vida del niño no está amenazada por su mal comportamiento. La madre que debe representar el papel de protectora, recurre sobre todo a halagos y a débiles amenazas, para mantener a sus hijos en línea. El padre exige más obediencia, está además más dispuesto a castigar al niño y la amenaza de su ira o ebriedad es suficiente para impedir que un niño se salga de la raya. La abuela materna y algunas veces también la abuela paterna, parecen dispuestas a pegar y a regañar a un niño para obligarlo a que obedezca, de modo que frecuentemente son invocadas por madres desesperadas que tratan de mejorar la conducta de sus hijos.

Algunas de las cosas por las que puede regañarse o castigarse a un niño es por mentiroso, flojo, peleonero, enojón, desobediente, por llorar demasiado, por jugar abiertamente con sus genitales, por pedir demasiados favores, por desobediencia a sus mayores o por tardar demasiado con un recado. Sin embargo, es raro que los niños se porten mal en esto.

Se cree que un niño menor de tres o cuatro años no obedecerá ninguna orden, si no recibe algún halago. Si el niño toca cosas que no debiera, la madre le advertirá que hay una serpiente lista para salir del rincón para morderlo. Si no obedece cuando se le dice que deje de lloriquear, de necear con el fuego, de ensuciarse, o bien que vaya a sentarse o que se esté quieto, provocará una amenaza de la madre que ni un niño de tres años creería del todo. Puede decir que un pariente borracho irá a cogerlo, o que un ladino irá y se lo llevará, que un toro irá a cornearlo, o que un cerdo irá a 
morderlo. La madre también puede quitar algo al niño de lo que le guste más y decirle por ejemplo, que va a salir a visitar a alguien o a cortar caña y que no lo llevará, o puede amenazarlo con que no le lavará el cabello. También puede amenazarlo con que no le responderá cuando le hable. Si esto sucede, resulta entonces un juego para el niño, un juego en el que trata de conseguir que la madre conteste, lo que naturalmente hace que se olvide de lo que estaba haciendo, exactamente lo que la madre quería. Otra forma es que la madre se queje de que ella misma será castigada por la mala conducta de su hijo, bien por su esposo o por su madre. Si la repetición de tales amenazas no resulta, la madre puede atraer al niño hacia ella y darle una cachetada o una nalgada juguetona, riéndose, tratando de impedir que el niño se ponga a llorar. Nunca presencié que se negara el pecho a los niños, ni como amenaza ni como castigo.

Cuando el niño es un poco mayor, se abandonan las amenazas del cerdo, el toro o el ladino, y el castigo corporal es un poco más severo cuando se aplica. Según el caso, el niño puede ser golpeado con una vara, la mano o una correa. Se puede llamar al padre para ejecutar este castigo. Pero es más usual explicar al niño los diferentes peligros sobrenaturales a los que está sujeto. Según la mayoría de los relatos, uno de estos peligros es el $b^{2} i b k^{\prime} a l$, un ser malvado, peludo y negro de aproximadamente un metro de estatura. Se dice que acecha a los niños que se pierden lejos de sus casas, que lloran mucho y que son desobedientes; además es un verdadero peligro para los adultos. A diferencia del duende norteamericano, el $b^{\text {Pib }} k^{\prime} a l$ es realmente temido y los adultos creen en su existencia. Muchos ruidos extraños de la noche se atribuyen al $b^{2} i b k^{\prime} a l$ que anda caminando por allí, cerca de la casa y tal vez tratando de entrar. De noche su nombre apenas sí se murmura, si es que se llega a pronunciar; existen muchas maneras eufemísticas de referirse al $b^{2} i b k^{\prime} a l$, como amenaza a los niños, por ejemplo, pues si llegara a oír su nombre cuando está afuera rondando, sin duda que entraría a hacer daño.

\section{Juegos}

Los niños reciben su primer juguete cuando tienen seis meses. Una pequeña calabaza llena con semillas secas (scuil $s k^{\prime} a b$ ) se amarra a la muñeca del niño. Esta calabaza suena como sonaja cuando el niño 
mueve el brazo y sirve para mantenerlo ocupado. Otras veces se amarra una cuerda con cuentas a su cintura. Para cuando el niño puede coger las cosas, se le han dado ya diferentes objetos para que juegue: una sonaja decorada, como las que se usan en carnaval, una piedra de forma extravagante, un pedazo de plástico para envolver, un pedazo de papel o tal vez alguna baratija comprada a los ladinos.

Pero aun antes de que tenga su primera sonaja, recibe estímulos de otros, además de su madre. Una vez que el niño tiene tres o cuatro meses, se considera correcto y hasta deseable jugar con él. Cuando la madre recibe visitas, éstas juegan con el niño, lo tocan, lo sienten y le hacen cosquillas. El niño se ríe, se mueve y parece que baila. Más tarde, cuando crece un poco más, comienza a gatear, poco al principio y más después. Pronto se para, aunque vacilante, algunas veces con la ayuda de un poste o de una banca. En esta etapa se le vigila constantemente para que no se caiga. Más tarde puede moverse más por sí mismo, y se detiene de objetos que encuentra a su paso.

A los dieciocho meses el niño ya camina un poco y comienza a explorar seriamente la casa donde vive. Constantemente toca cosas que se le ha advertido no tocar, pero su curiosidad natural no se satisface, así que las advertencias no tienen más que un efecto momentáneo, aunque las entienda. El niño es mucho más curioso a los dos años y medio, cuando se le permite jugar afuera con un hermano o primo mayor, siempre vigilado por la madre. Cuando comienza a hablar, llegan nuevas oportunidades para jugar. El niño imita a su madre, trata de tararear y cantar como ella, dice palabras algunas derivadas del español, que evocan la risa de la madre y gusta mucho con el juego de pegarse mutuamente en las manos, pellizcar, hacer cosquillas y esconderse, ya sea con mamá o un hermano mayor.

Parece que a niños muy chicos gustan mucho las breves fórmulas verbales repetitivas, fórmulas que rápidamente aprenden de sus padres y de otras personas. Se cree por ejemplo, en diferentes áreas de Tenejapa, que una oruga (čup) vendrá y morderá a la persona que deje sin terminar un elote cuando han comenzado a desprender sus granos, a menos que alguien llegue y pellizque el dorso de las manos de todos y diga lik lik lik. Por lo menos tres veces he oído a niños de menos de tres años pedir a su madre o hermanos que jueguen "lik lik lik", habiendo visto sólo una o dos veces antes cómo se juega. Este rápido aprendizaje parece implicar una gran 
motivación. Los niños mayores también parecen gustar de estas fórmulas verbales. Tienen por ejemplo, un remedio contra los ronquidos; consiste en sostener una lagartija (š $k^{\prime}$ intun) tres veces consecutivas, bajo la nariz del paciente, pronunciando cada vez la frase sok sok $n$ ? . Esta misma fórmula se emplea para limpiar la nariz tapada de un bebé de dos o tres semanas de nacido. Una vez me encontraba en una vereda con dos hermanas de cuatro y cinco años, cuando vimos a un šk'intun o lagartija. Bastó que las niñas la vieran, para que inmediatamente pusieran sus dedos una bajo la nariz de la otra, riéndose y diciendo sok sok $n \vec{\imath}$. Pasaron algunos minutos antes de que el juego decayera.

Una vez que el niño ha cumplido tres o cuatro años, se le permite salir a jugar con otros niños por un buen rato, aunque no deberá alejarse de la casa y rara vez tendrá la oportunidad de jugar con más de seis o siete niños. No es raro que un niño tenga sólo dos o tres compañeros de juego. En compañía de amigos, hermanos u otros parientes cercanos, los niños exploran el reino de la naturaleza: trepan a los árboles, juntan flores, con los tallos de las plantas hacen silbatos, recogen bayas y se las comen, encuentran y molestan a los insectos, hacen guitarras de juguete de las piñas de pino, de la corteza de plátano (pobčil lo $\mathrm{P} \mathrm{bal}$ ) hacen sandalias de juguete, detienen pequeñas corrientes para jugar en ellas y avientan piedras.

Además de las actividades de explorar y explotar la naturaleza, tienen otros pasatiempos de tipo social, como seguir al primero, jugar a "la roña" y una variedad del escondite (nak'ton bba). Entre los niños es común jugar a las luchas, así como entre las niñas lo es el perseguirse y caer. Parece que jugar a la "pelota" con una lima dulce o una naranja tiene un gran número de variaciones (por ejemplo: jugar a cacharla, a perseguir la pelota, a tratar de pegarle a un blanco), y es muy popular. Algunos niños encuentran en sus casas pelotas viejas de caucho, traídas por uno de los padres para jugar. Niños y niñas brincan, corren, saltan, se deslizan y dan vueltas hasta marearse, algunas veces solos, pero más a menudo en grupo.

Niños y niñas juegan juntos hasta que tienen siete años, después de lo cual los juegos entre ambos sexos disminuyen considerablemente. Ya desde antes, las niñas prefieren jugar con niñas y los niños con niños, aunque el que sean tan pocos los niños que son vecinos en casi toda la región, no siempre les permite esta selección. Niños mayores juegan gustosos con niños más chicos, si faltan sus compañeros. 
La mayoría de los niños chicos juegan con canicas y trompos hechos en casa. Algunos juegan con una hélice que hacen los ladinos, a la que se da vueltas en la mano hasta que sale volando. Casi todos los niños tienen una honda. El padre le hace una a su hijo antes de que éste tenga siete u ocho años, después, el niño ya puede hacerse las suyas. Las hondas se hacen de una rama ahorquillada de cafeto, guayabo, naranjo o cualquier árbol apropiado y se ajusta con bandas de hule que se compran en el mercado. Los niños juegan con sus hondas hasta que tienen doce años o más. Algunos niños fabrican también pistolas de bambú, que disparan pedazos de basura a corta distancia, por medio de un pedazo de bambú doblado que salta hacia adelante cuando se libera. Más común es una cerbatana (tubk'alte?) que hace ruido. Se hace ahuecando un tallo de algunos centímetros de longitud, de ciertas plantas, por el cual se lanzan después pedazos de médula.

Las niñas prefieren jugar a cuidar una mazorca de maíz que visten con una falda de hoja y una banda de corteza de plátano. Un pedazo de tela sustraído del hogar, puede servir como rebozo para cargar la muñeca. Las niñas hablan a las muñecas, les hacen caricias y generalmente las cuidan como cuidarían a un hermano menor. En muchos casos, las niñas comienzan su juego con muñecas con un hermanito, más que con una muñeca. También juegan a hacer tortillas de lodo y usan un tiesto como comal. Hacen un fuego imaginario en un hogar de tres piedras y cuidadosamente hacen las tortillas de lodo antes de ponerlas en el comal de juguete.

El aspecto imitativo del juego de los niños de Tenejapa es muy notorio y los adultos tzeltales lo saben bien. Se dice que los niños imitarán cualquier cosa que vean hacer a los adultos. Habiendo visto que toman ron, los niños se pasarán por turnos una botella llena de agua; al mismo tiempo que toman, pronuncian las palabras rituales y las respuestas, ambas tan importantes cuando los adultos beben verdadero licor. Como también los han visto hacer casas, los niños pedirán prestado un machete, cortarán tablones de la corteza del plátano, la paja para el techo de hojas de plátano y los colocarán en un marco de ramas y postes para hacer su propia casa de juguete. También han visto matar a los toros y cortar su carne en partes proporcionales; en este caso, los niños utilizarán el tronco caído de un plátano como toro y pequeños cuchillos de bambú para trinchar los pedazos de "carne" que envuelven después en hojas de plátano que van apilando. 
Uno de los juegos imitativos más comunes es el de ser o cuidar a un toro. Niños y niñas caminan en pies y manos como toros, mueven la cabeza e imitan el mugido profundo y quejumbroso del toro. Un niño puede tomar un pedazo de reata y amarrar otra a un arbusto, o puede amarrarse unos cuernos de bambú en la cabeza y bailar, afirmando que está haciendo la "danza del toro", que realiza un adulto durante el carnaval $\left(l o^{2} i l\right)$. Otras veces se utiliza como toro un pedazo redondo de tronco con una reata amarrada. Se lleva por allí, se ata a un árbol o arbusto, se lleva a abrevar a alguna corriente, etcétera, imitando el cuidado del padre por su toro de verdad. Muchas veces, este juego degenera en empujar al toro-tronco colina abajo para verlo rodar y después en empujarlo de regreso. Y así como juegan a ser el toro, juegan a que son o tienen un caballo. Caminan en pies y manos y relinchan como caballos. Algunas veces montarán una vara o rama como si fuera un caballo, otras veces un niño se sentará en una banca baja (c'amalte?) de la casa mientras otro lo empuja alrededor de la misma.

La preparación política se da cuando los niños juegan a ser las autoridades en la jerarquía de los cargos de Tenejapa; éste es uno de sus pasatiempos favoritos. El niño que es el "presidente" (bkunarol) dice a sus "diputados" (brebroletik) que vayan y metan a un niño a la cárcel, tal y como sucede en la vida real en las fiestas. Hay muchas variaciones en el tema de las "autoridades", pero las partes que más gustan a los niños es repetir las frases que usan los adultos cuando persiguen a alguien para llevarlo nuevamente a la cárcel.

Otro juego en el que se representan papeles, se relacionan generalmente con modelos animales. Un grupo de niños forma un corral, tomándose todos de los brazos. Un niño entra y no se le permite salir. A este niño se le llama čib (borrego/venado). Otro niño brinca alrededor por fuera del corral y cuida al que está adentro. A este niño se le llama c'i (perro). Aunque este juego también es muy popular, los adultos no hacen nada que se le parezca. Tal vez se base en la práctica tzotzil de juntar un rebaño de ovejas.

Algunas veces, cuando las niñas tienen ocho años o más comienzan a jugar juegos relativos al sexo y al matrimonio. Un grupo de niñas que encontré una vez accidentalmente, estaba sentado en un platanar; la guía estaba pasando plátanos verdes a las otras niñas y decía, "esta es tu esposa, esta es tu esposa y esta es mi esposa", hasta que a cada una se le había designado el cuidado de su propia "esposa-plátano". Más tarde se cambiaron los papeles, cambiando los plátanos en esposos borrachos. Es aproximadamente 
a esta edad que las niñas buscan y usan un pequeño insecto vermicular llamado "hormiga león" del género myrmeleon (butbut 'itčan) que se supone ponen en sus pezones para que los muerda y haga que los pechos les crezcan más.

\section{Trabajo}

Aunque puede considerarse que muchos de los juegos de los niños son una preparación para el trabajo y las relaciones sociales, partes del papel que desempeña un adulto en la sociedad, los niños comienzan a participar directamente, al aprender estos aspectos de la cultura a la edad de dos años y medio, cuando entienden y pueden hablar ya un poco. Esta participación es en parte simple observación de primera mano, y en parte, el desempeño de tareas domésticas, al principio en una escala menor y entre ratos de puro juego. Más tarde, con la edad, llega más trabajo y más responsabilidad como parte ya de la unidad económica familiar.

La primera manifestación de la ayuda de un niño con las tareas del hogar, nace de sus intentos de imitar jugando los actos de la madre o algún hermano mayor. Un niño de treinta meses tratará, muy mal al principio, de soplar para obtener una llama del fuego, de mover la comida que se está cocinando, de servir agua, de tirar pedazos de tortilla a los pollos que entran a la casa en busca de comida, de levantar las cosas que la madre le pide, de sacar de la casa a las gallinas, de dar las verduras a los conejos de la familia que viven en la casa, y otras cosas que es posible imitar. Guiado por la madre y algunas veces a pesar del fastidio que le causa, el niño habrá adquirido mayor habilidad en estas tareas a la edad de tres años. Para entonces el niño habrá acompañado a su madre en pequeñas correrías para juntar leña, recoger verduras comestibles y frutas, cortar caña, ir por agua a un río o corriente cercana y buscar los huevos que las gallinas hayan puesto. Tal vez, a los tres años, un niño ya fue a algún mercado distante o a San Cristóbal. Sin duda ya habrá ido a visitar a los parientes para pedir prestado o habrá acompañado a su madre que iba solamente a platicar.

A la edad de cuatro años el niño puede resultar una gran ayuda para su madre en trabajos menores; la ayuda a barrer la casa, a alimentar a las gallinas, a cuidar al hermanito, a llevar pequeñas cargas de leña y jarras de agua de la fuente, si lo acompaña la madre o un hermano mayor. Las niñas comienzan a hecer tortillas, 
a desgranar el maíz y hasta a molerlo en el metate. Los niños comienzan a pasar más tiempo afuera, ayudando a la madre cuando se necesita y jugando cuando pueden. Niños y niñas aprenden a matar las pulgas que se encuentran en las cobijas que se sacan periódicamente al sol para airearlas. Las habilidades que el niño comienza a usar cuando ayuda a su madre, van aumentando año con año y a la edad de seis o siete hay muchas cosas que el niño ya puede hacer solo. El padre puede enseñar a su hijo a esta edad cómo hacer su primera bolsa tejida (čobak') con la fibra del maguey. Una niña puede comenzar a aprender a tejer. Niños y niñas habrán ido a la milpa con sus padres en varias ocasiones, y habrán participado en alguna forma en las tareas de sembrar o limpiar la milpa. A partir de este momento, un niño comenzará a acompañar a su padre a la milpa, regularmente. Puede ser que vaya también cuando el toro o la mula de la familia vayan a ser cambiados, y en algunos viajes al centro de Tenejapa a la fiesta o al mercado de los domingos.

A los ocho o nueve años, el niño es capaz de trabajar en el campo con su padre en una escala menos limitada. Si no quiere hacerlo, una vez que tiene la edad suficiente, es posible que lo azoten. Se piensa que de otro modo se echaría a perder, se volvería flojo y nunca aprendería a ocupar el lugar de un adulto en la sociedad. Una niña de ocho o nueve años puede sustituir a su madre en los mandados, puede barrer y algunas veces moler el maíz. Si todavía no ha aprendido a tejer, es este el momento de comenzar. También puede ir sola a traer agua a una fuente cercana, aunque todavía no pueda llevar una carga.

Es raro que se haga, pero una familia pobre puede vender un niño a un ladino, una vez que el niño pueda trabajar, ya sea a los seis o a los siete años. Un ladino paga en la región, de cincuenta a cien pesos o dos cochinos chicos, y pone a trabajar al niño en el centro de Tenejapa, que es donde viven los ladinos.

\section{Escuela}

Además de trabajar y jugar, algunos niños van a la escuela. El paraje de Mahosik' tiene una escuela con dos maestros indígenas residentes (uno de Bachajón y el otro de Oxchuc). La escuela es para los niños de seis a catorce años, aunque una reciente campaña del INI (Instituto Nacional Indigenista), trató de interesar a los jóvenes para que vayan a aprender español por las tardes. La escuela 
opera sobre una base semirregular de semanas de cinco días con frecuentes intervalos en los que los maestros van a San Cristóbal. Teóricamente, las clases comienzan a las nueve de la mañana y terminan como a las cuatro de la tarde. Muchos largos recesos interrumpen el día.

La educación formal en la escuela hace hincapié en el aprendizaje del español por medio de ejercicios de repetición de las conjugaciones, memorización de frases simples, aprendizaje de canciones y otros tipos de enseñanza. Se enseñan los rudimentos de la escritura, además, conocimientos básicos de aritmética, dibujo, biología, cuentas, decir la hora e higiene. El alfabeto español se ha adaptado al tzeltal para la lectura de textos elementales del INI en tzeltal, aunque la lectura y escritura en español se enseñan como meta final. El niño también aprende algo de la historia y geografía de Chiapas y México para participar, de labios para afuera, de un sentimiento de unidad nacional, aunque el aislamiento de la comunidad indígena, excluye cualquier sentimiento profundo de mexicanidad.

Una de las funciones secundarias de la escuela, es formar un partido de jugadores de basket-ball de niños del paraje, para que compitan los sábados con equipos de otros parajes. Los juegos del hogar atraen a muchos niños de edad escolar y a niños más pequeños que vienen a mirar. Los juegos en parajes cercanos atraen a muchos niños que siguen tanto al maestro como a su equipo a una comunidad vecina, para pasar el día viendo el juego y aplaudiendo a su equipo.

Aunque hay ciento veinticinco niños en edad escolar en Mahosik', es raro el día que aparecen siquiera sesenta en la escuela. En algunos casos, los padres quieren que los hijos se queden en casa y ayuden al trabajo en la milpa y en la casa misma. Otros padres desconfían del valor de la educación, especialmente para sus hijas. Muchos niños temen ir solos a la escuela o simplemente no les gusta y sus padres se resisten a obligarlos a ir. Si los niños que van a la escuela en un día determinado no parecen ser suficientes al maestro, éste reunirá a los niños que ya se encuentran en la escuela e irá por el paraje a las casas donde hay niños en edad escolar, tratando de llevarse a los delincuentes por medio de presión social. Después regresa a la escuela con algunos niños más y comienza la clase.

Año con año, el inspector del INI viene a la escuela por un día o dos, para evaluar las enseñanzas del maestro y el progreso de los alumnos. Durante los días que el inspector permanece en la escuela, 
hay diversiones que incluyen títeres y discos. En estos días, la mayoría de los niños del paraje van a la escuela para las festividades.

Pero la escuela se está convirtiendo con cada año que pasa en una experiencia de mayor influencia en las vidas de los niños de Tenejapa. El número de profesores indígenas ha aumentado, sobre todo por los esfuerzos del INI. Estos maestros son entrenados por el INI y generalmente hablan el español con fluidez. Con la disminución de maestros ladinos, conocidos como malos maestros, crueles y oportunistas a costa de los indios, los niños han comenzado a aprender cosas más importantes, con personas más amables. Con el contacto entre indígenas y costumbres occidentales, que aumenta paulatinamente, las fuerzas de aculturación desempeñan una gran influencia en la comunidad indígena. Las objeciones de los padres a una educación formal para sus hijos, es cada vez menos enérgica, y los niños de las generaciones actuales tienen más opciones que sus antepasados. Estos cambios y la comunicación en aumento por medio de radios y carreteras, están allanando el camino a un proceso previsible de rápida aculturación que ha comenzado apenas. Mientras tanto, muchos de los viejos usos continúan casi imperturbables.

\section{Adolescencia y matrimonio}

La infancia desemboca suavemente en la adolescencia (tek'leh) como a los doce o trece años. Las jóvenes se vuelven modestas y evitan el contacto con jóvenes en sus juegos. Éstos pasan todavía bastante tiempo jugando, especialmente basket-ball, pero ya dejan la honda y muchos de sus juegos anteriores.

Las relaciones entre ambos sexos se vuelven más reservadas y delicadas. El periodo de solidaridad intra-sexual, termina tras un lapso de experimentación juvenil, en el sutil juego del cortejo, con sus propias rutinas y reglas de interacción. Un cortejo serio sustituye a la experimentación después de un tiempo, y culmina en uniones informales y matrimonios.

Es raro que un muchacho o una muchacha se casen al comenzar la adolescencia. El matrimonio es más común entre los jóvenes de dieciocho o veinte y las muchachas de dieciséis o dieciocho. Con el matrimonio termina el ciclo de la infancia y la pareja se prepara para tener hijos y educarlos dentro del marco de costumbres $\mathrm{y}$ tradiciones que conformaron sus propias vidas. 


\section{CONCLUSION}

Los patrones de interacción que caracterizan a la infancia, se pueden trazar a partir de la discusión anterior y aumentar en una serie de observaciones generales. La casa relativamente aislada y el jardín que la rodea, es el mayor aspecto geográfico en el espacio vital del niño pequeño. El tamaño del jardín puede variar mucho, pero gran parte de la interacción social ocurre en el claro al que se abre la puerta de entrada de la casa. La superficie de este patio ('amak') varía de $18 \mathrm{~m}^{2}$ hasta cinco o seis veces más. La limitación del espacio vital del niño a la casa y patio, es mucho menos marcada a medida que crece. Con sus hermanos mayores, el niño de dos o tres años comienza a explorar las zonas vecinas, en círculos cada vez más amplios; a los cinco o seis, lo hace solo. Mientras tanto, habrá acompañado a su madre o a algún hermano responsable en sus visitas a otras casas, en viajes al mercado, en mandados, a fuentes de agua, experimentando visualmente una variedad de aspectos ambientales y asimilando conceptos de distancia y dirección.

Las visitas se hacen durante el día y una familia en promedio recibe una o dos visitas al día, generalmente de parientes. Personas no emparentadas vienen con mucha menor frecuencia, generalmente en visitas de negocios y rara vez hablan con un niño menor de cinco años. En cambio, un pariente puede llevar a uno o varios de sus hijos que pueden establecer una relación con el bebé. Si el niño visitante es tres o cuatro años mayor, la relación puede tener las características de juego. Si las visitas son parientes cercanos, los adultos hablarán al niño, generalmente dándole órdenes, haciéndole preguntas o dando respuestas a sus preguntas. El habla infantil casi no existe en Tenejapa.

El niño escucha el habla en casa durante el día, especialmente si hay visitas. En la noche escucha el habla de adolescentes y adultos en la casa, cuando se reúnen alrededor del fuego para intercambiar noticias y relatos verbales y para discutir las actividades del día. Cuentos con su moraleja, leyendas y restos de información cultural se dirigen generalmente al niño que tiene edad para atenderlos y muchas de las preguntas de los niños se responden con historias tradicionales. Por otra parte, es difícil que el niño asimile el habla escuchada si está jugando.

El niño entre los dos y seis años tendrá sin duda uno o más hermanos con quienes interactuar, y gran parte de esta interacción 
será verbal, siendo el niño mayor el guía o maestro, a quien el niño menor sigue e imita. La imitación se extiende a la esfera verbal, y aunque un niño mayor casi nunca corrige los errores verbales del hermano menor, éstos se reproducen con burlas. De uno a tres años aproximadamente, se permite a un niño jugar en la casa o el patio con un hermano mayor, aunque por breves lapsos. El hermano mayor puede hasta llevarlo un poco lejos de la casa, pero también sólo por momentos. Los pensamientos de la madre acompañan al niño siempre que éste se encuentra fuera de su vista.

Desde que nace hasta que llega a los dos años, el niño está casi siempre en compañía de su madre, envuelto en pañales, en el regazo de la madre o en la cama, y la mayoría del tiempo en la espalda de la madre, envuelto en su rebozo. Después del año y medio o de los dos años, se le permite caminar cerca de la madre, dentro o fuera de la casa; la madre mantiene el contacto verbal con sólo breves intervalos. Después de los dos años, el niño puede pasar algún tiempo al cuidado de la abuela materna, lo que permite a la madre realizar libremente algunas tareas. Aunque otros hermanos y parientes pueden entrar en la vida de un niño sobre una base verbal después de los dos años, es la madre quien dạ la mayor información lingüística, por lo menos hasta que el niño tiene tres o cuatro años. Compañeros y otros niños forman un segmento siempre en aumento de las fuentes de información linguística en esta época. A los cinco o seis años, son ellos quienes asumen la dirección del tiempo del niño y son los responsables de su información verbal. Las niñas tienden a quedarse en casa con la madre o alguna parienta, aprendiendo a hacer tortillas, a cantar, a tejer, o participando en otras actividades femeninas. Los niños en cambio, comienzan a dedicar gran parte de su tiempo a juegos fuera de la casa y exploraciones con parientes y compañeros de la misma edad, ayudando más tarde a sus padres en las tareas propias de su sexo y en la escuela. Después de los seis o siete años, algunas niñas también van a la escuela, pero son la minoría.

En realidad, el padre habla poco al niño pequeño, pues no es mucho el tiempo que pasa en casa durante el día, excepto cuando se repone de una cruda o cuando cuida el jardín, repara la casa o en domingos y días excepcionalmente fríos o lluviosos. Cuando habla al niño, la situación es más formal que cuando la madre y el niño se encuentran solos. El padre pregunta y responde, lo mismo que pide o da órdenes. Ocasionalmente corregirá al niño si éste ha pronunciado mal una palabra o la está empleando mal. La formalidad 
relativa en la interacción padre-hijo, se debe en parte al papel protector de la madre y ejecutor del padre.

Las formas que toma la interacción social respecto a un niño, las frecuencias, los que participan y las escenas, todos son responsables de los tipos y cantidades de lenguaje que oye un niño que está creciendo y que toma en consideración inconscientemente en el proceso de la adquisición del conocimiento y los hábitos que llamamos reglas lingüísticas y sociolingüísticas. Los patrones de interacción que se refieren sólo a los adultos, también tienen un efecto en los tipos y cantidades de lenguaje que escucha un niño.

Un examen del lenguaje dirigido a los niños por los adultos, sugiere que la variedad de estructuras gramaticales representadas, se limita sobre todo a órdenes, preguntas simples y exclamaciones. De aquí que, exceptuando la existencia de un poderoso componente innato de universales lingüísticos, formales y sustantivos, como lo propusieron McNeil (1966: 50) y otros, parece más bien que los niños de tres o cuatro años tienen un dominio más limitado de la esfera de estructuras lingüísticas posibles de lo que se había creído antes (cf. McNeil, 1966:15), o que el lenguaje escuchado desempeña un papel mucho más importante en la adquisición del lenguaje que lo que se creía generalmente (cf. Hattori, 1965).

Vista como un todo, la educación de los niños en Tenejapa se puede caracterizar sucintamente como permitiendo amplias posibilidades de desarrollo, orientada maternalmente en los primeros años, informal y relativamente flexible dentro de los límites impuestos por los peligros potenciales a la salud y alma del niño. Esta orientación tiene efectos claros y obvios sobre la información lingüística que se da al niño. Determinantes indirectos del lenguaje a los que está expuesto el niño, incluyen factores socioculturales, tales como el patrón de ajuste, el sistema de parentesco que los une, los restos de linaje del clan de tiempos antiguos, la atmósfera de brujería y envidia que penetra en las relaciones sociales, el mundo de los espíritus, la importancia del alma, la división de trabajos por sexo, los hábitos de beber del hombre y muchas influencias menos evidentes que dirigen los patrones de interacción y determinan la naturaleza de las normas de educación de los niños.

\section{APÉNDICE A: Etapas tzeltales en el desarrollo del niño}

1. yič'ob makel 'alal - concepción

2. bunbil 'alal - etapa fetal 
a) ya šlibk nibkuk - comienza a moverse

b) ya šlibk buk'ubabuk - comienza a hacer ruidos, a hipar

c) ya šlibk šk'ušul - comienza a causar dolores

d) ya štobk - nace ( ya šp'ebkab - cae)

3. 'alal tutin - bebé, infante

a) ya '̌'ok' 'alal - el bebé llora ('uneh, 'uneb - sonido del niño que llora) cf. ' $a,{ }^{?} a-$ niño llorando e ${ }^{2},{ }^{2} i-$ adulto llorando.

b) ya šlibk yil k'abk' - comienza a ver el fuego

c) ya šlibk Pilawanuk - comienza a mirar a su alrededor

d) ya šlibk šbalč'un sba - comienza a moverse y a dar vueltas

e) ya šlibk scelk'un sba - comienza a ponerse de lado

f) ya šlibk bibp'awetel - comienza a moverse en el rebozo

g) ya šlibk ščošan sba - comienza a levantarse, con las piernas derechas, sobre pies y manos

b) ya šlibk kotlabetuk - comienza a gatear

i) ya šlibk hamuk stì - comienza a abrir la boca (a arrullar y balbucear)

j) $y a$ šlibk šmačan sba - comienza a acercarse a las cosas

k) ya šlibk p'eč - comienza a ponerse en pie

l) ya šlibk spas čolčolte? - comienza a caminar vacilante, apoyándose en diversos objetos

m) ya šlibk benuk lek - comienza a caminar bien

n) ya šlibk hamiš lek stï - comienza a abrir bien la boca (primeras palabras claras)

o) ya šlibk k'opobok - comienza a decir palabras

p) ya šlibk k'opobok ta sp'alap'al - comienza a decir frases

q) ya šlibk snop 'a $a^{2} y e b-$ comienza a aprender a hablar, a platicar

4. kerem, 'ačiš - niño, niña

a) č'in kerem, ě'in 'ač ' $2 \check{\mathrm{S}}$ - niñito, niñita

Esta etapa comienza cuando el niño ya habla bien (ya sna? ? $a^{2}$ yeb), como a los dos y medio o tres años. Se puede llamar al niño simplemente kerem o 'ač $i s$ s. Ya habla bien y puede correr, pero es muy chico para hacer mandados.

b) muk'ul kerem, muk'ul 'ač' $i$ š — niño grande, niña grande

Esta etapa comienza cuando el niño ya puede hacer mandados, como a los seis años. Todavía se le puede decir kerem o solamente 'ač' $i$ š.

5. tek'leb - adolescente

Esta etapa abarca de los trece o catorce hasta los dieciocho o 
diecinueve años, o hasta el matrimonio. Durante este tiempo se puede llamar č'iom 'ač 'iš a una muchacha.

6. winik, ?anc - hombre, mujer

Esta etapa comienza generalmente con el matrimonio. Este término no se puede aplicar a una persona muy joven casada, pero sí a una persona soltera ya grande (entre los veinte y veinticinco).

\section{BIBLIOGRAFIA}

Guiteras-Holmes, C.

1961 Perils of the Soul, Glencoe.

HATTORI, S.

1965 "The Sound and Meaning of Language", en Foundations of Language, 1: 95-111.

JOHNSON, J. B.

1939 "The Elements of Mazatec Witchcraft", en Etnologiska Studier, 9: $128-150$.

LENNEBERG, E.

1967 Biological Foundations of Language, Nueva York.

MCNEILL, D.

1966 "Developmental Psycholinguistics", en The Genesis of Language: A Psycholinguistic Approach, ed. por F. Smith y G. A. Miller, pp. 151-84, Cambridge.

REDFIELD, R. y A. VILLA ROJAS

1934 Chan Kom: A Maya Village, Chicago. (Edición abreviada: Chicago, 1962.) 